\title{
Ammonium Salts as a Source of Small Molecules Observed with High- Resolution Electron-Impact Ionization Mass Spectrometry
}

Nora Hänni1, ${ }^{1}$, Sébastien Gasc ${ }^{1}$, Adrian Etter ${ }^{1}$, Markus Schuhmann, Isaac Schroeder ${ }^{1}$, Susanne F. Wampfler ${ }^{2}$, Stefan Schürch ${ }^{3}$, Martin Rubin ${ }^{1}$, Kathrin Altwegg $^{1}$

${ }^{1}$ Physikalisches Institut, University of Bern, Sidlerstrasse 5, CH-3012 Bern, Switzerland

${ }^{2}$ Center for Space and Habitability, University of Bern, Gesellschaftsstrasse $6, \mathrm{CH}-3012$ Bern, Switzerland

${ }^{3}$ Department of Chemistry and Biochemistry, University of Bern, Freiestrasse 3, $\mathrm{CH}-3012$ Bern, Switzerland

* Correspondence to E-mail: nora.haenni@space.unibe.ch; Tel.: +41 316315914.

"This document is the unedited Author's version of a Submitted Work that was subsequently accepted for publication in The J ournal of Physical Chemistry A, copyright (c) American Chemical Society after peer review. To access the final edited and published work see https://pubs.acs.org/doi/10.1021/acs.jpca.9b03534."

\section{Abstract}

Recent high-resolution in situ mass spectrometry at comet 67P/Churyumov-Gerasimenko visited by European Space Agency's Rosetta spacecraft raised the question, if sublimating ammonium salts can unequivocally be detected in the cometary coma. In laboratory experiments with the twin model of the space instrument, two prototypic ammonium salts $\mathrm{NH}_{4} \mathrm{~B}$, 
namely ammonium chloride $\left(\mathrm{B}=\mathrm{Cl}^{-}\right)$and ammonium formate $\left(\mathrm{B}=\mathrm{HCOO}^{-}\right)$(as well as methodologically relevant isotopologues), were allowed to sublimate in vacuum while mass spectra were collected. High-resolution electron-impact ionization mass spectrometry provides an outstanding experimental tool to investigate the complex physico-chemical processes occurring during the sublimation of ammonium salts. Sublimation of ammonium chloride led to the observation of the ammonium cation $\mathrm{NH}_{4}{ }^{+}$and the chloramide molecule $\mathrm{NH}_{2} \mathrm{Cl}$ in the neutral gas mode of the instrument. These observations could be jointly interpreted as indirect evidence for the existence of a neutral gaseous parent species (either as the molecular complex $\mathrm{NH}_{3} \ldots \mathrm{HB}$ or the double-ionic species $\left.\mathrm{NH}_{4}{ }^{+} \ldots \mathrm{B}^{-}\right)$. However, the qualitative fragmentation pattern we present for ${ }^{13} \mathrm{C}^{15} \mathrm{~N}$-ammonium formate suggests an alternative route of $\mathrm{NH}_{4}^{+}$production within the ionization region of the instrument, namely by protonation/hydrogenation. Besides $\mathrm{NH}_{4}{ }^{+}$, other species were observed which were formed in protonation/hydrogenation reactions. Moreover, together with the two major species from the decomposition of the salt, ammonia and formic acid, three minor species also contributed to the fragmentation pattern: HCN/HNC, $\mathrm{HOCN} / \mathrm{HNCO}$, and $\mathrm{CH}_{3} \mathrm{NO}$. Like chloramide, formamide $\left(\mathrm{CH}_{3} \mathrm{NO}\right)$ also is a secondary species probably formed in a pseudo-intramolecular chemical reaction while ammonia and the respective acid are in a state of association. $\mathrm{HCN} / \mathrm{HNC}$ and $\mathrm{HOCN} / \mathrm{HNCO}$ are ternary products coming out of formamide decomposition reactions. We discuss our experimental findings, summarized in a tentative chemical reaction network, in light of the available theoretical literature and highlight their relevance for the interpretation of in situ measurements in space research. 


\section{Introduction}

This work was motivated by the tentative identification of ammonium-bearing minerals on the surfaces of Mars $^{1}$ and of the asteroid Ceres $^{2-3}$ by remote sensing from orbit. Quirico et al. (2016) interpreted a broad dip at $3.2 \mu \mathrm{m}$ in the infrared absorption spectrum measured by the VIRTIS instrument on the surface of 67P/Churyumov-Gerasimenko (hereafter 67P) as being compatible with carboxylic groups in organic molecules and/or the ammonium ion. ${ }^{4}$ This raised the question if ammonium salts, for instance ammonium formate, could be detected based on their sublimation products in the cometary coma of 67P by the ROSINA mass spectrometer suite which is, like VIRTIS, part of the European Space Agency's Rosetta mission. In situ highresolution mass spectrometry has the potential to resolve ambiguities encountered with infrared remote sensing, where the signatures, being relatively broad absorption features, were far from specific. ${ }^{5}$ However, a thorough understanding of the sublimation processes of ammonium salts and subsequent fragmentation in an electron-impact ionization (EI) mass spectrometer (MS) is prerequisite.

The sublimation mechanism and gas phase structure of ammonium chloride $\left(\mathrm{NH}_{4} \mathrm{Cl}\right)$, probably the prototypic ammonium salt, have been debated over more than a century. In this section, we provide the reader with a brief historical summary of the most relevant work on the topic. The Gmelin Handbook of Inorganic Chemistry ${ }^{6}$ and literature cited therein discuss ammonium chloride as a dissociating compound with decay temperatures of around $340^{\circ} \mathrm{C} .{ }^{7-8}$ The reported degrees of dissociation into ammonia $\left(\mathrm{NH}_{3}\right)$ and hydrochloric acid $(\mathrm{HCl})$ in the gas phase range from undissociated (e.g. Ref. 9) to partially dissociated (e.g. Ref. 10) to completely dissociated (e.g. Refs. 7-8 and 11). Ab initio calculations investigated the electronic structure of the $\mathrm{NH}_{4} \mathrm{Cl}$ molecule and its possible dissociation products $\mathrm{NH}_{3}, \mathrm{HCl}, \mathrm{NH}_{4}^{+}$, and $\mathrm{Cl}^{-}$. Using extended basis sets of Gaussian type orbitals, Clementi (1967) found an energetic minimum in the $\mathrm{NH}_{4} \mathrm{Cl}$ 
potential surface occurring $19 \mathrm{kcal} / \mathrm{mol}$ below the energy of its most stable dissociation products $\mathrm{NH}_{3}$ and $\mathrm{HCl}^{12}{ }^{12}$ In 2007, Zhu et al. investigated the kinetics and sublimation mechanism of the ammonium chloride system in a first-principles study, using a generalized gradient approximation in the plane-wave density functional theory for their calculations. ${ }^{13}$ Statisticaltheory calculations indicate that desorption of the $\mathrm{NH}_{3} \ldots \mathrm{HCl}$ molecular complex (instead of the individual molecules) from a relaxed crystal surface is energetically favored and rate-controlling. The authors thus revised the desorption mechanism previously proposed by Knacke et al. (1951) in which $\mathrm{NH}_{3}$ and $\mathrm{HCl}$ desorb separately and independently. ${ }^{14}$ In 1969, Goldfinger and Verhaegen tested the theory using a commercial ULTEK quadrupole mass spectrometer with a $32 \mathrm{eV}$ El source..$^{15}$ They analyzed the equilibrium vapor effusing from a Knudsen cell containing solid $\mathrm{ND}_{4} \mathrm{Cl}$. Highly sensitive mass-spectrometric methods seemed suitable considering that the amount of undissociated $\mathrm{NH}_{4} \mathrm{Cl}$ at $352^{\circ} \mathrm{C}$ was estimated to be less than $0.5 \% \cdot{ }^{16}$ Goldfinger and Verhaegen performed measurements between 62 and $212^{\circ} \mathrm{C}$ and argued that the signal registered on mass $22 \mathrm{u}$ was due to the deuterated ammonium ion $\left(\mathrm{ND}_{4}^{+}\right)$, which itself must have had originated from the gaseous neutral ammonium chloride parent. ${ }^{15}$ However, to date, direct detections of gaseous species with masses higher than the $\mathrm{HCl}$ isotopologues remain unachieved. The National Institute of Standards and Technology (NIST) Chemistry WebBook database ${ }^{17}$ borrows the ammonium chloride mass spectrum from the National Institute of Advanced Industrial Science and Technology (AIST) Spectral Database for Organic Compounds (SDBS), ${ }^{18} \mathrm{cf}$. Table S1 in the supplementary material. The heaviest species therein is the $\mathrm{HCl}$ isotopologue $\mathrm{D}^{37} \mathrm{Cl}$ at $\mathrm{m} / \mathrm{z}=39$.

The simple organic ammonium salt ammonium formate $\left(\mathrm{NH}_{4} \mathrm{OOCH}\right)$, our second target compound, bridges the inorganic and the organic worlds. The Gmelin Handbook of Inorganic Chemistry ${ }^{19}$ and the literature cited therein reports melting of ammonium formate under decomposition in the range of $112-117^{\circ} \mathrm{C}$. To date, the El fragmentation pattern of ammonium 
formate has not been published. The AIST standard mass spectrum of ammonium acetate (SDBS No. 1633), measured at a sample temperature of $120^{\circ} \mathrm{C}$ (just above the melting/decomposition range of $110-120^{\circ} \mathrm{C}^{20}$ ) and at a source temperature of $160^{\circ} \mathrm{C}$, shows that the salt decays mainly into acetic acid $(\mathrm{m} / \mathrm{z}=60,65.1 \%$ relative intensity (r.i.)) and ammonia ( $\mathrm{m} / \mathrm{z}=17,73.4 \%$ r.i.). Analogously, ammonium formate is expected to decay mainly into ammonia and formic acid. According to AIST (SDBS No. 10523), formic acid $\left(\mathrm{CH}_{2} \mathrm{O}_{2}, \mathrm{~m} / \mathrm{z}\right.$ $=46,100 \%$ r.i. $)$ mainly fragments into $\mathrm{CHO}_{2}(\mathrm{~m} / \mathrm{z}=45,66.4 \%$ r.i. $)$ and $\mathrm{CHO}(\mathrm{m} / \mathrm{z}=29,58.2 \%$ r.i.). Two additional decay pathways are expected, namely, decarboxylation into $\mathrm{CO}_{2}$ and $\mathrm{H}_{2}$ and dehydration into $\mathrm{H}_{2} \mathrm{O}$ and $\mathrm{CO}$. In two theoretical studies, both reactions were reported to have similar energy barriers of between 63 and $71 \mathrm{kcal} / \mathrm{mol} .^{21-22} \mathrm{In}$ the formic acid reference mass spectrum, $\mathrm{m} / \mathrm{z}=44\left(\mathrm{CO}_{2}\right)$ shows a signal with $14.6 \%$ r.i., $\mathrm{H}_{2}$ at $\mathrm{m} / \mathrm{z}=2$ is out of range, $\mathrm{m} / \mathrm{z}=18\left(\mathrm{H}_{2} \mathrm{O}\right)$ shows a signal with $18.0 \%$ r.i., and $\mathrm{m} / \mathrm{z}=28(\mathrm{CO})$ has $13.0 \%$ r.i. According to NIST (NIST MS no. 69$), \mathrm{CO}_{2}$ is expected to fragment into $\mathrm{CO}(\mathrm{m} / \mathrm{z}=28$, about $10 \%$ r.i.), but this fragmentation does not sufficiently explain the $\mathrm{CO}$ signal observed for formic acid. If contamination of the signal on $\mathrm{m} / \mathrm{z}=28$ by $\mathrm{N}_{2}$ is excluded, then dehydration/decarbonylation must be a competitive gas phase reaction pathway of formic acid. Moreover, very minor signals of $<0.5 \%$ r.i. are observed at $\mathrm{m} / \mathrm{z}=55$ and several other higher $\mathrm{m} / \mathrm{z}$-values up to $\mathrm{m} / \mathrm{z}=109$ in the formic acid standard mass spectrum. These could indicate aggregation of two or more formic acid molecules, which is strong enough to persist in the gas phase and even during ionization. However, in contrast to the standard data reported for ammonium chloride (sample temperature $=140^{\circ} \mathrm{C}$, source temperature $=210^{\circ} \mathrm{C}$ ) as well as to our experiments, the data reviewed and discussed in this paragraph was collected from decomposing liquid samples (instead of sublimating solid samples as performed in this work). The physico-chemical processes occurring during desorption from the crystal surface are explicitly different from the 
ones occurring during desorption from a decomposing liquid phase. This is expected to reflect in the observed species and thus the fragmentation pattern.

In this article, we report on the first high-resolution El mass spectra of two sublimating ammonium salts: ammonium chloride and ammonium formate (and methodologically relevant isotopologues). The following section describes in detail the two different experimental set-ups used to investigate the two target compounds and the strategy employed in evaluating the data.

Section 3. presents and discusses our experimental findings and section 4. summarizes and concludes the work. In addition to (indirectly) investigating the basic properties and processes related to sublimating ammonium salts, our aim was to set a precedent for the in situ identification of ammonium salts that may be present in cometary atmospheres and evaporating cometary dust particles. We believe this article and the data presented herein contribute significantly to the debate within the cometary science community as to whether ammonium salts are an extended source of ammonia and hence an abundant species in comets (see e.g. Ref. 23).

\section{Experimental}

\subsection{Instrument Description and Data Evaluation}

The Double Focusing Mass Spectrometer (DFMS) is a sector field EI-MS built in the MattauchHerzog configuration ${ }^{24}$. The electron energy of $45 \mathrm{eV}$ is substantially lower than the standard electron energy of $70-75 \mathrm{eV}$ used for NIST and AIST reference spectra. Fragmentation of gaseous species occurs alongside $\mathrm{El}$ in the ion source, producing the singly charged cations 
of interest to us (for reasons of simplicity, the positive charge produced under El will not be indicated). Lower electron energies are expected to produce higher relative yields of the parent molecule as compared to their fragments. This has to be considered when the data to follow is compared with standards provided by either of the aforementioned databases.

DFMS has a mass resolution of $\mathrm{m} / \Delta \mathrm{m}=3000$ (at $1 \%$ peak height for $\mathrm{m} / \mathrm{z}=28$ ) and nominally covers an m/z-range from 12 to 180 . It registers the charge deposited by two Chevron Micro Channel Plates (MCPs) on two Linear Electron Detector Array (LEDA) anodes with 512 pixels each. More information on the instrument and on the scientific context of its design may be found in Balsiger et al. (2007). ${ }^{25}$

Laboratory experiments were performed with a twin instrument identical to the DFMS in space (part of the ROSINA instrument package onboard European Space Agency's Rosetta spacecraft). Masses were measured in high-resolution with the instrument's neutral gas modes. In these modes, ambient positive ions are repelled by a positively biased ion suppressor plate around the entrance of the ion source, while negatively charged ions are accelerated toward the plate. The latter, however, are also unable to enter the DFMS' ionization source box as it is set to a negative potential. Samples were generally measured with standard operating modes whereby a range of masses per unit charge would be scanned in sequence with an integration time of $20 \mathrm{~s}$ per spectrum. Natural and deuterated ammonium chloride samples were also measured via direct command mode with an integration time of $1.98 \mathrm{~s}$ per spectrum. 100 spectra were then averaged prior to further data processing to enhance the counting statistics. A suitable set of potentials was applied for each mass-to-charge ratio and the voltage across the MCPs was adjusted to ensure optimal amplification while avoiding saturation. In this way, the gain could be varied in-between measurements, granting a wide dynamic range spanning 10 orders of magnitude. Recorded detector counts were converted to number of ions per spectrum during data evaluation by division by the overall gain produced by the applied 
amplification voltage. An overall gain and pixel gain correction to account for detector aging was also applied. We accounted a total error of $20 \%$ for the gain and pixel gain corrections in our error estimation. An additional error of $10 \%$ is further introduced by the subtraction of a variable (usually $3^{\text {rd }}$ order polynomial) offset from the spectra before the individual peaks were fitted and integrated.

Fits were performed based on a least squares fitting routine, with usually a double Gaussian fit to each peak. Best reproduction of the characteristic peak shape of DFMS peaks was obtained when the second Gaussian (g2) was about 5-10\% of the height of the main Gaussian (g1) and $300-400 \%$ of its width. Width and height ratios of the two Gaussians remain constant within the same mass spectrum. To simplify the error propagation calculations, the error of the fit was set to an average error of $50 \%$ for strongly overlapping peaks and to an average error of $20 \%$ for well-defined peaks. The appropriateness of this approach was tested on the ammonium chloride data and then extended to the ammonium formate data. Finally, the peak areas obtained from the least squares fitting routine were corrected for instrument sensitivity. The instrument sensitivity is proportional to $(\mathrm{m} / \mathrm{z})^{-0.8}$ (error estimate: $20 \%$ ). For the estimation of the total error on the number of ions observed per spectrum, the error introduced by the counting statistics turned out to be very minor and was thus neglected. We have not corrected for the differences in ionization cross-sections given that these are not available in the literature for all the observed species.

\subsection{Set-Up and Measurement Details}

Ammonium chloride and its isotopologues were allowed to sublimate at several temperatures between room temperature (RT) and about $125^{\circ} \mathrm{C}$ in a separate specifically built heating chamber. This chamber was directly connected with a flange to the ionization chamber of 
DFMS, as shown in the scaled Figure S1(top) in the supplementary material. The heater was comprised of two ceramic tubes on two supporting steel pins and a Kanthal heating wire wound around the tubes 12 times. A glass melting point tube (inner diameter: $1 \mathrm{~mm}$ ) containing the sample material was affixed to the heating wire. The sample's temperature was estimated by measuring electrical resistance with a Pt100 element situated between heating wire, ceramic tubes, and sample tube. Pressure stability in the ionization region of DFMS was achieved by controlling and adjusting the temperature manually. The room temperature vapor pressure of ${ }^{13} \mathrm{C}^{15} \mathrm{~N}$-ammonium formate was substantially higher than the one of ammonium chloride and no heating was necessary to achieve a pressure on the order of $10^{-7}$ mbar inside the ionization chamber of DFMS. Hence, the sample was put in a glass tube with an inner diameter of $5 \mathrm{~mm}$ in place of the heating chamber. The tube was directly connected to the DFMS ion source via a leak valve and the pressure controlled electronically with a Pfeiffer Vacuum RVG050C valve control, cf. Figure S1(bottom). The pressures generated in the DFMS ionization chamber during our experiments were notably lower than the pressures in the sample container (about 2 orders of magnitude for ammonium chloride and 3-4 orders of magnitude for ammonium formate). The higher pressures in the sample area lead to higher collision rates of species (with chamber walls and/or other gas phase species) compared to the ionization region. In the case of ammonium formate, additionally minor effects of the narrow valve passage on the fragmentation pattern are expected. Both issues would require separate and detailed investigations under an experimental-technical point of view, which go beyond the scope of this work.

The main pressure monitor was a Granville-Phillips hot cathode pressure gauge (Stabil Ion 370120, EEPROM BD166) located directly above the ion source of DFMS. As the GranvillePhillips pressure gauge values had been calibrated with $\mathrm{N}_{2}$, the experimental pressures had to be corrected. Assuming a gaseous mixture of $50 \% \mathrm{NH}_{3}$ and $50 \% \mathrm{HCl}$, we divided the measured 
pressure data for $\mathrm{NH}_{4} \mathrm{Cl}$ with an average gas correction factor of 1.4. This we obtained from averaging factors for $\mathrm{NH}_{3}$ (1.3) and $\mathrm{HCl}$ (1.5), extracted from a compilation published by $\mathrm{R}$. L. Summers (1969). ${ }^{26}$ Likewise, for the ammonium formate experiments we assumed a gaseous mixture of $50 \% \mathrm{NH}_{3}$ and $50 \%$ formic acid. As no gas correction factor has been published for formic acid, we made an attempt to estimate it by comparing the total ionization cross-section of formic acid (4.0 $\AA^{2}$ at $\left.75 \mathrm{eV}^{27}\right)$ with that of $\mathrm{N}_{2}\left(2.548 \AA^{2}\right.$ at $\left.75 \mathrm{eV}^{28}\right)$. The resulting factor of 1.5 is inaccurate, mostly because the gas in the Granville-Phillips gauge is ionized at $150 \mathrm{eV}$. The average gas correction factor for ammonium formate was thus assumed to be 1.4. The pressures for the investigated isotopologues of ammonium chloride and ammonium formate were corrected with the same gas correction factors. For the pressure gauge itself, an absolute accuracy of $\pm 4 \%$ and a repetition accuracy of $\pm 3 \%$ was specified. ${ }^{29}$ Relevant pressures were measured in the low range mode of the gauge.

\subsection{Sample Preparation}

Crystals of $\mathrm{NH}_{4} \mathrm{Cl}$ (Merck, puriss p.a., sublimated at $260^{\circ} \mathrm{C}$ in air) and ${ }^{15} \mathrm{NH}_{4} \mathrm{Cl}$ (Reseachem/Cambridge Isotope Laboratories, $>99 \%{ }^{15} \mathrm{~N}$, used as purchased) were ground into a powder and filled into a glass melting point tube. The deuterated ammonium chloride sample (ARMAR, >99\% D, used as purchased) was prepared accordingly. In order to prevent exchange of the deuterium with hydrogen from water and air, the preparative work was carried out under an inert atmosphere in a glove box (Braun, $\mathrm{H}_{2} \mathrm{O}$ and $\left.\mathrm{O}_{2}<0.1 \mathrm{ppm}\right)$. The sample was transported in a glass tube sealed under inert atmosphere and the exposure to air during the mounting procedure was minimized to a few seconds.

${ }^{13} \mathrm{C}^{15} \mathrm{~N}$-ammonium formate was crystallized from a solution of ${ }^{13} \mathrm{C}$-formic acid (Reseachem/Cambridge Isotope Laboratories, $<5 \% \mathrm{H}_{2} \mathrm{O}, 99 \%{ }^{13} \mathrm{C}$ ) and ${ }^{15} \mathrm{~N}$-ammonium 
hydroxide (Reseachem/Cambridge Isotope Laboratories, $3.3 \mathrm{~N}$ in $\mathrm{H}_{2} \mathrm{O},>98 \%{ }^{15} \mathrm{~N}$ ) by slow evaporation. Without additional purification, the structure and purity of the dry product material was confirmed by X-ray powder diffraction. The diffraction pattern is shown in Figure S2 in the supplementary material. For the experiments, the hygroscopic colorless polycrystalline material was filled into a $5 \mathrm{~mm}$ inner diameter glass tube connected to a flange.

\section{Results and Discussion}

\subsection{Species from Sublimating Ammonium Chloride}

Several data sets were collected with natural $\mathrm{NH}_{4} \mathrm{Cl}$ at different pressures. We will focus on data collected at $\mathrm{p0}=(5 \pm 1)^{\star} 10^{-9}$ mbar, which corresponds to a room temperature measurement, and at $\mathrm{p} 4=(8.9 \pm 0.3)^{\star} 10^{-8} \mathrm{mbar}$, which corresponds to a measurement at a sample temperature of about $90^{\circ} \mathrm{C}$. The ranges of the pressures indicated in brackets, here and in the following, are due to the achievable precision for manual temperature regulation and include neither the error related to the overall gas correction factor nor the uncertainty due to the pressure gauge itself. From the collected mass spectra, the relative abundances of species originating from the sample were established based on the p4 data set. The qualitative results are summarized in Figure 1 and Table S2 in the supplementary material. 


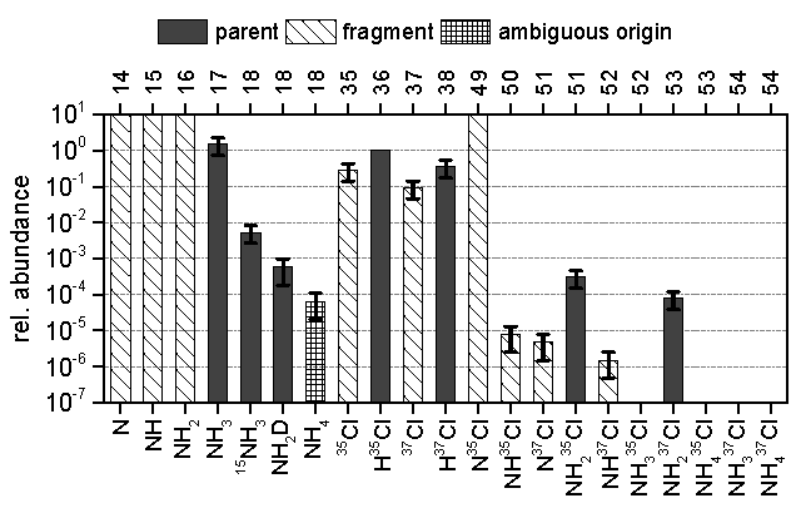

Figure 1. Abundances of ammonium chloride related species relative to $\mathrm{H}^{35} \mathrm{Cl}$ (directly comparable to numbers listed in Table S1). The top scale specifies the integer masses of the species given in the bottom scale and end-to-end bars indicate fragment species whose relative abundances have not been determined. All species were observed upon sublimation of the sample at a temperature of about $90^{\circ} \mathrm{C}$, corresponding to the ionization chamber being at pressure p4. The exact values are listed in Table S2.

According to the data in Figure 1, sublimation/fragmentation processes of $\mathrm{NH}_{4} \mathrm{Cl}$ mainly lead to the observation of ammonia and hydrochloric acid and fragments thereof. This was expected, based on the reference mass spectrum in Table S1. The parent species $\mathrm{NH}_{4} \mathrm{Cl}$ itself was not detected, as shall be expounded in the subsequent paragraph. However, Zhu et al. (2007) proposed co-desorption of $\mathrm{NH}_{3}$ and $\mathrm{HCl}$ in the form of an associated molecular complex $\mathrm{NH}_{3} \ldots \mathrm{HCl}^{13}$ In this molecular complex, a proton back-transfer from $\mathrm{HCl}$ to $\mathrm{NH}_{3}$ may occur, which would yield an ionic complex of the form $\mathrm{NH}_{4}{ }^{+} \ldots \mathrm{Cl}^{-}$. Upon dissociation, the $\mathrm{NH}_{4}{ }^{+}$and $\mathrm{Cl}^{-}$ ions are obtained and $\mathrm{NH}_{4}$ was indeed observed. As only neutral species are able to enter the ion source of DFMS (cf. subsection 2.1. for details), the dissociation of the neutral complex must occur inside the ionization chamber of DFMS. In order to enter the ionization region, this neutral complex must persist long enough in the gas phase to travel about $30 \mathrm{~cm}$ and pass an aperture of $2 \mathrm{~cm}$ diameter, cf. scaled Figure S1(top). However, Zhu et al. calculated that 
desorption is the rate-controlling step and dissociation should be fast. ${ }^{13}$ Below, we thus suggest an alternative explanation for the observation of the ammonium cation, more in line with the findings of Zhu et al. The p4 mass spectrum around $m / z=18$ in Figure S3(a-b) clearly shows residual intensity on the right slope of the $\mathrm{NH}_{2} \mathrm{D}$ peak $(\mathrm{m} / \mathrm{z}=18.0323)$ at the exact position of $\mathrm{NH}_{4}(\mathrm{~m} / \mathrm{z}=18.0338)$. Introducing an additional Gaussian at the exact position of $\mathrm{NH}_{4}$ decreases the reduced $x^{2}$ value of the overall fit. Despite the small signal of $\mathrm{NH}_{4}{ }^{+}$with a relatively large estimated error due to uncertainties introduced by the data correction procedure, we could reproduce the observation of the ammonium ion consistently in all our experiments, cf. subsections 3.2. and 3.3. Hence, our data is well in line with observations reported by Goldfinger and Verhaegen. ${ }^{15}$ The complex mass spectra of sublimating ammonium formate, presented and discussed in subsection 3.3., show various species that are likely formed by protonation/hydrogenation. This could as well be the case for $\mathrm{NH}_{4}^{+}$. Formation of $\mathrm{NH}_{4}{ }^{+}$by protonation/hydrogenation of $\mathrm{NH}_{3}$ is explicitly different from the previously proposed formation mechanism involving the neutral complex of $\mathrm{NH}_{3} \ldots \mathrm{HB}$ or $\mathrm{NH}_{4}^{+} \ldots \mathrm{B}^{-}$. The observed temperature/pressure dependence of the ammonium signal, shown in Figure S3(c), is compatible with either scenario of origin. 

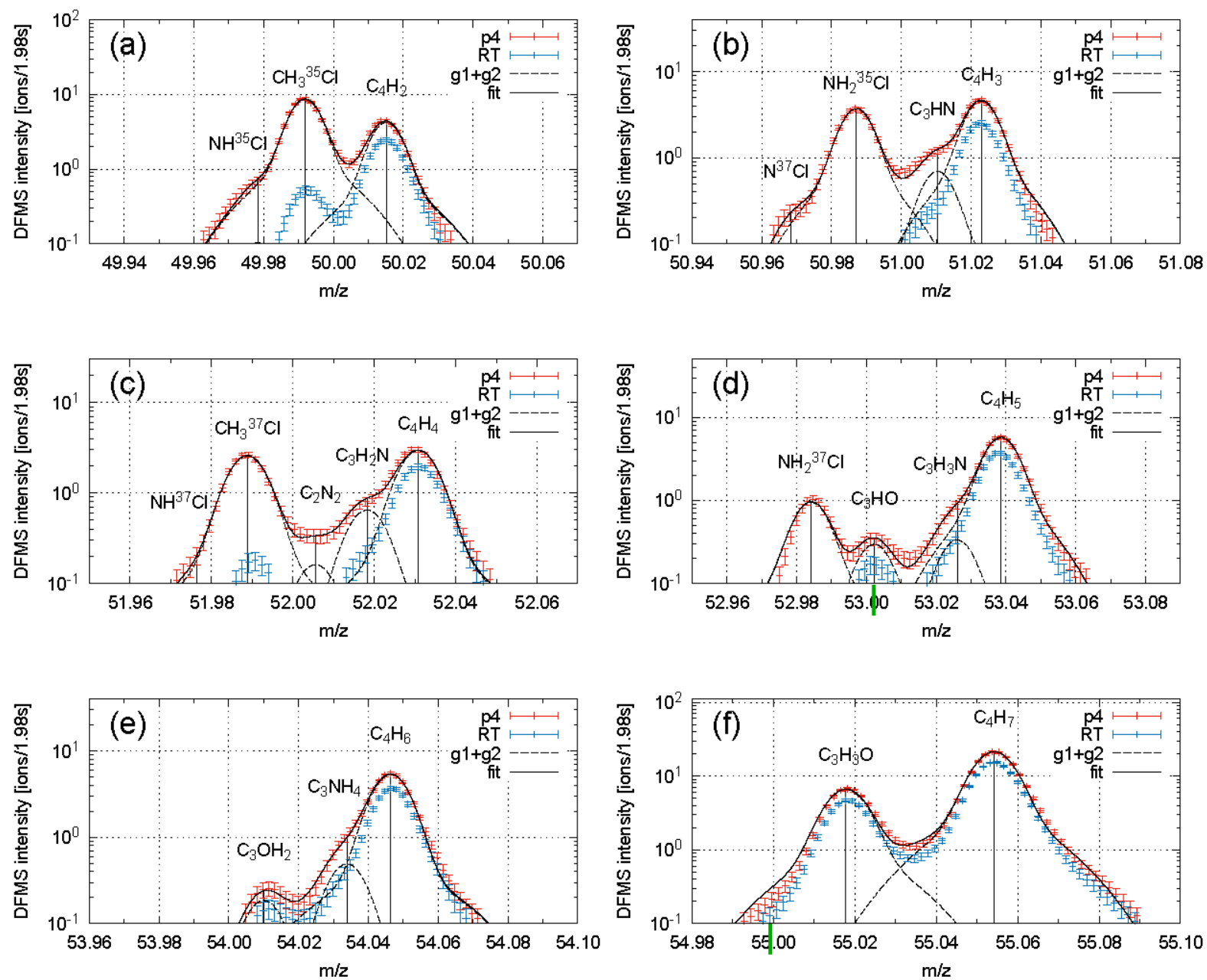

Figure 2. Fitted p4 mass spectra (red) of $\mathrm{NH}_{4} \mathrm{Cl}$ for $\mathrm{m} / \mathrm{z}=50-55$ reveal the presence of $\mathrm{NH}_{2} \mathrm{Cl}$. For reasons discussed in the main text, the two isotopologues of the gaseous parent compound $\mathrm{NH}_{4} \mathrm{Cl}$ (calculated positions indicated with green bars) can be ruled out. Room temperature data (blue) is included to show the temperature evolution of the various species. Species containing atoms other than $\mathrm{H}, \mathrm{N}$, and $\mathrm{Cl}$ are background-related (cf. subsection 3.2.).

In Figure 2(a-f) the mass spectra of $\mathrm{m} / \mathrm{z}=50-55$ are plotted. This data shows that the gaseous parent compound, $\mathrm{NH}_{4}{ }^{35} \mathrm{Cl}$ at $\mathrm{m} / \mathrm{z}=53.0027$ in Figure 2(d) and $\mathrm{NH}_{4}{ }^{37} \mathrm{Cl}$ at $\mathrm{m} / \mathrm{z}=54.9997$ in Figure 2(f), if present, did not contribute to the spectra within detection limits. The pressure dependence of the $\mathrm{C}_{3} \mathrm{HO}$ signal at $\mathrm{m} / \mathrm{z}=53.0022$ (position coincides with that of $\mathrm{NH}_{4}{ }^{35} \mathrm{Cl}$ ) 
indicates a sample-independent origin. A slight increase in the signal strength with increasing pressure inside the ionization chamber is observed for all species and is attributed to enhanced desorption of residual species from the walls. A detailed discussion of the background (mainly hydrocarbons) and related experimental artifacts will follow in subsection 3.2. Though no signal is observed within limits of detection at the expected position of $\mathrm{m} / \mathrm{z}=54.9997$ for $\mathrm{NH}_{4}{ }^{37} \mathrm{Cl}$, markedly pressure-dependent signals at $\mathrm{m} / \mathrm{z}=50.9871$ and $\mathrm{m} / \mathrm{z}=52.9841$ indicate the presence of chloramide $\mathrm{NH}_{2} \mathrm{Cl}$ (cf. Figure 2(b,d)). The derived $\mathrm{NH}_{2}{ }^{35} \mathrm{Cl} / \mathrm{NH}_{2}{ }^{37} \mathrm{Cl}$ ratio is 3.9 ( \pm 2.0 ), consistent within the error bars with the terrestrial abundance of ${ }^{35} \mathrm{Cl} /{ }^{37} \mathrm{Cl}=3 \cdot 1 \cdot{ }^{30} \mathrm{NH}_{2} \mathrm{Cl}$ apparently follows two fragmentation pathways, yielding either $\mathrm{NH}_{2}$ and $\mathrm{Cl}$, or $\mathrm{NHCl}$ and $\mathrm{H}$. $\mathrm{NHCl}$ subsequently fragments into $\mathrm{NH}$ and $\mathrm{Cl}$ or $\mathrm{NCl}$ and $\mathrm{H}$. We observed traces of all $\mathrm{NCl}-$ conserving fragments of chloramide within the measured $\mathrm{m} / \mathrm{z}$-range (Figures 1 and 2 and Table S2). As the mean free path between two unassociated molecules is about $1 \mathrm{~km}$ at $1 \star 10^{-7} \mathrm{mbar}$, gas phase collisions are highly unlikely. Even in the sample chamber, where the pressure was rather about $1 * 10^{-5}$ mbar, the mean free path still is of the order of $10 \mathrm{~m}$. Thus, formation of $\mathrm{NH}_{2} \mathrm{Cl}$ must occur during the desorption process or in the gas phase while $\mathrm{NH}_{3}$ and $\mathrm{HCl}$ are in a state of association. In this sense, the reaction is competitive to the proton back-transfer reaction mentioned earlier in this section. Table S2 shows the ion yields per unit time for $\mathrm{NH}_{4}$ and $\mathrm{NH}_{2} \mathrm{Cl}$ to be of the same order of magnitude (disregarding possible differences in the ionization cross-section).

A comparison of Tables $\mathrm{S} 1$ and $\mathrm{S} 2$ reveals a decreased $\mathrm{H}^{35} \mathrm{Cl} /{ }^{35} \mathrm{Cl}$ ratio $(\sim 3.5)$ with respect to the AIST data ( 7.9). The standard $\mathrm{HCl}$ mass spectrum from the NIST database (NIST MS no. 18847) yields an $\mathrm{H}^{35} \mathrm{Cl} /{ }^{35} \mathrm{Cl}$ ratio of 5.9. Following the scenario outlined above, we suspect a relatively long-lived associated $\mathrm{NH}_{3} \ldots \mathrm{HCl}$ (or $\mathrm{NH}_{4}{ }^{+} \ldots \mathrm{Cl}$ ) complex, which is dissociating at least partially inside the ionization region of DFMS to yield the observed $\mathrm{NH}_{4}$ (and a stoichiometric amount of $\mathrm{Cl}$ ). However, the $\mathrm{Cl}$ signal is higher than expected, when compared with estimates 
based on the sum of the $\mathrm{NH}_{4}$ and $\mathrm{NH}_{2} \mathrm{Cl}$ (partially fragments into $\mathrm{Cl}$ ) signals. A qualitative explanation for this could be that a relevant portion of the neutral $\mathrm{NH}_{4}{ }^{+} \ldots \mathrm{Cl}^{-}$complex is decaying outside of the ionization region. Because of the design of the instrument, $\mathrm{Cl}^{-}$produced in this way would be accelerated toward the ion source box. There, if neutralized to $\mathrm{Cl}$ upon collision with the chamber walls, it is able to enter the ionization region. The positively charged $\mathrm{NH}_{4}{ }^{+}$, in contrast, is repelled by the ion suppressor plate and hence not detected.

\subsection{Isotopologues of Ammonium Chloride}

Two isotopologues of ammonium chloride were measured to reproduce the observations and investigate the interaction of sample species with background species. $\mathrm{ND}_{4} \mathrm{Cl}$ was measured at three different pressures $\left(\mathrm{p} 0 / \mathrm{RT}=(5 \pm 1)^{\star} 10^{-9} \mathrm{mbar}, \mathrm{p} 1=(6.3 \pm 0.3)^{\star} 10^{-8} \mathrm{mbar}\right.$, and $\mathrm{p} 2=$ $\left.(5.2 \pm 0.3)^{\star} 10^{-7} \mathrm{mbar}\right)$, while ${ }^{15} \mathrm{NH}_{4} \mathrm{Cl}$ was measured at two different pressures $\left(\mathrm{p} 0 / \mathrm{bg}=(4 \pm 1)^{\star} 10^{-}\right.$ ${ }^{9}$ mbar, and p1 $=(1.0 \pm 0.2)^{\star} 10^{-7}$ mbar $)$. Spectra presented in Figure 3 show peaks of (a) ND 4 at $\mathrm{m} / \mathrm{z}=22.0589$ and (b) ${ }^{15} \mathrm{NH}_{4}$ at $\mathrm{m} / \mathrm{z}=19.0309$ without other interfering signals. Interestingly, the $\mathrm{H}_{3} \mathrm{O}$ signal in Figure 3(b) increases by about factor 12 between $\mathrm{p} 0$ and $\mathrm{p} 1$, while the signals of the other background species increase by a factor 3-5 only. This implies that water molecules inside the ionization region of DFMS are protonated increasingly during our experiment. Not only is the observation of the ammonium ion reproducible, but also the occurrence of chloramide. Figure 4 qualitatively confirms the presence of the chloramide isotopologues (a) $\mathrm{ND}_{2} \mathrm{Cl}$ at $\mathrm{m} / \mathrm{z}=52.9996$ and $\left(\right.$ b) ${ }^{15} \mathrm{NH}_{2} \mathrm{Cl} \mathrm{m} / \mathrm{z}=51.9841$. 

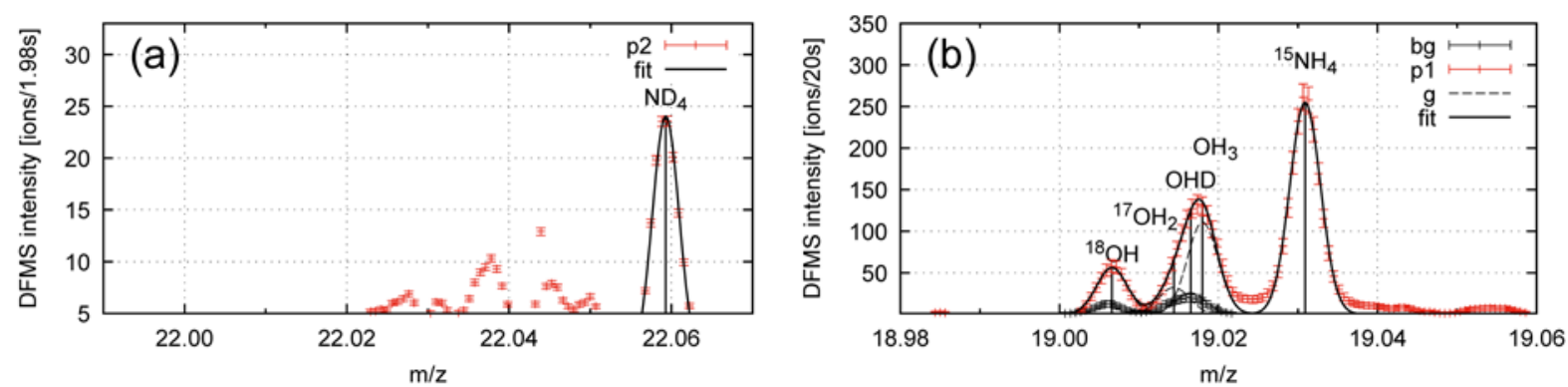

Figure 3. (a) Plot of the mass spectrum of $\mathrm{ND}_{4} \mathrm{Cl}$ at $\mathrm{p} 2$ and $\mathrm{m} / \mathrm{z}=22.100$ spectra were averaged for an enhanced signal/noise ratio. A peak is observed at the expected position of ND4. (b) Plot of the mass spectrum of ${ }^{15} \mathrm{NH}_{4} \mathrm{Cl}$ at $\mathrm{p} 1$ (red) and $\mathrm{m} / \mathrm{z}=19$. A peak is observed at the expected position of ${ }^{15} \mathrm{NH}_{4}$, which was not seen in the background (black) of the empty heating chamber.
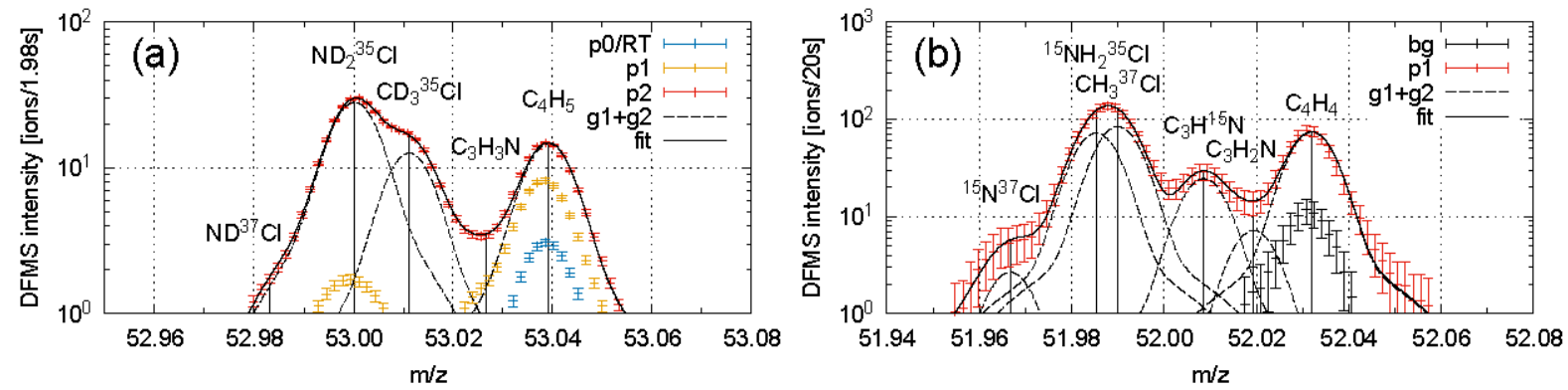

Figure 4. (a) Plot of the p0/RT < p1 < p2 mass spectra collected on $\mathrm{ND}_{4} \mathrm{Cl}$ at $\mathrm{m} / \mathrm{z}=53.100$ spectra were averaged for a better signal/noise ratio. Pressure-dependent signals are appearing at the expected positions of deuterated chloramide $\mathrm{ND}_{2}{ }^{35} \mathrm{Cl}$, as well as deuterated chloromethane $\mathrm{CD}_{3}{ }^{35} \mathrm{Cl}$. (b) Plot of the mass spectrum of ${ }^{15} \mathrm{NH}_{4} \mathrm{Cl}$ at $\mathrm{p} 1$ (red) and $\mathrm{m} / \mathrm{z}=52$. A peak is appearing at the expected position of ${ }^{15} \mathrm{NH}_{2}{ }^{35} \mathrm{Cl}$, which was not seen in the background (black) of the empty heating chamber. 
A general remark on the mainly hydrocarbon based background species in DFMS and related artifactual effects observed in our experiments shall conclude this subsection: Various background species, which were also present in the spectra presented in Figure 2 (e.g. $\mathrm{C}_{n} \mathrm{H}_{\mathrm{x}} \mathrm{O}$ or $\mathrm{C}_{\mathrm{n}} \mathrm{H}_{\mathrm{x}}$ species, where $\mathrm{n}$ is the number of $\mathrm{C}$-atoms and $\mathrm{x}$ the number of $\mathrm{H}$-atoms), have their origins in earlier calibration experiments performed on DFMS with saturated and unsaturated pure hydrocarbons, alkanols, carboxylic acids, and a few other small organic molecules. ${ }^{31-32}$ Their abundances when compared to the main species from the sublimating salts, i.e. ammonia and the respective acid, are on the order of $1^{\star} 10^{-5}$. Other than the signals of sample species, their signals increase only slightly with increasing pressure of the decomposing salts and the observed increase is mainly due to the overall change in the temperature of the apparatus facilitating desorption from the walls. However, there are a few examples of artifactual species with signals similarly temperature-dependent like the signals of sample species. The plot in Figure 4(a) for instance shows the production of deuterated chloromethane $\mathrm{CD}_{3}{ }^{35} \mathrm{Cl}$ during the experiment. Deuterated chloromethane must have formed either in a collision-induced chemical reaction of the associated complex of deuterated ammonia and deuterated hydrochloric acid with hydrocarbon species adsorbed to the walls or from impurities contained in the sample material (<1\% impurities specified, cf. subsection 2.3.). The same origin can be assumed for species like $\mathrm{C}_{3} \mathrm{H}^{15} \mathrm{~N}$ (see Figure 4(b)), which also exposes a prominent temperature dependence. Given the occurrence of isotope-mixed artifactual species (e.g. $\left.{ }^{12} \mathrm{C}^{15} \mathrm{~N}\right)$ in experiments with rare isotope-enriched ${ }^{13} \mathrm{C}^{15} \mathrm{~N}$-ammonium formate $(<1 \%$ impurities and $>99 \%$ enrichment specified for the starting materials, cf. subsection 2.3.), reactions of sample species with residual species from calibration experiments seem more likely. Clearly further investigations would be necessary to fully clarify the origin of the observed artifactual species. 


\subsection{Species from Sublimating ${ }^{13} \mathrm{C}^{15} \mathrm{~N}$-Ammonium Formate}

To better resolve the direct products of the salt from the background and artifactual species, rare isotope-enriched ${ }^{13} \mathrm{C}^{15} \mathrm{~N}$-ammonium formate was prepared in accordance with the procedure described in subsection 2.3. Its sublimation/decomposition is expected to produce ${ }^{15} \mathrm{~N}$-ammonia and ${ }^{13} \mathrm{C}$-formic acid as major gas phase species. Measurements were performed at room temperature and with the ionization chamber of DFMS at pressure $\mathrm{p} 1=(2.1 \pm 0.3)^{\star} 10^{-7}$ mbar. Data was corrected and integrated as previously described in subsection 2.1. and the background was subtracted. Figure 5 summarizes the abundances of the major sample-related species relative to ${ }^{15} \mathrm{NH}_{3}$. The corresponding numbers (including minor species such as ${ }^{18} \mathrm{O}$ isotopologues) are listed in Table S3 in the supplementary material. Errors from fitting signals in the slopes of large peaks, together with uncertainties introduced by data correction processes, led to large overall errors. The error estimation is detailed in subsection 2.1. and estimated errors for individual species have been included in Table S3. 


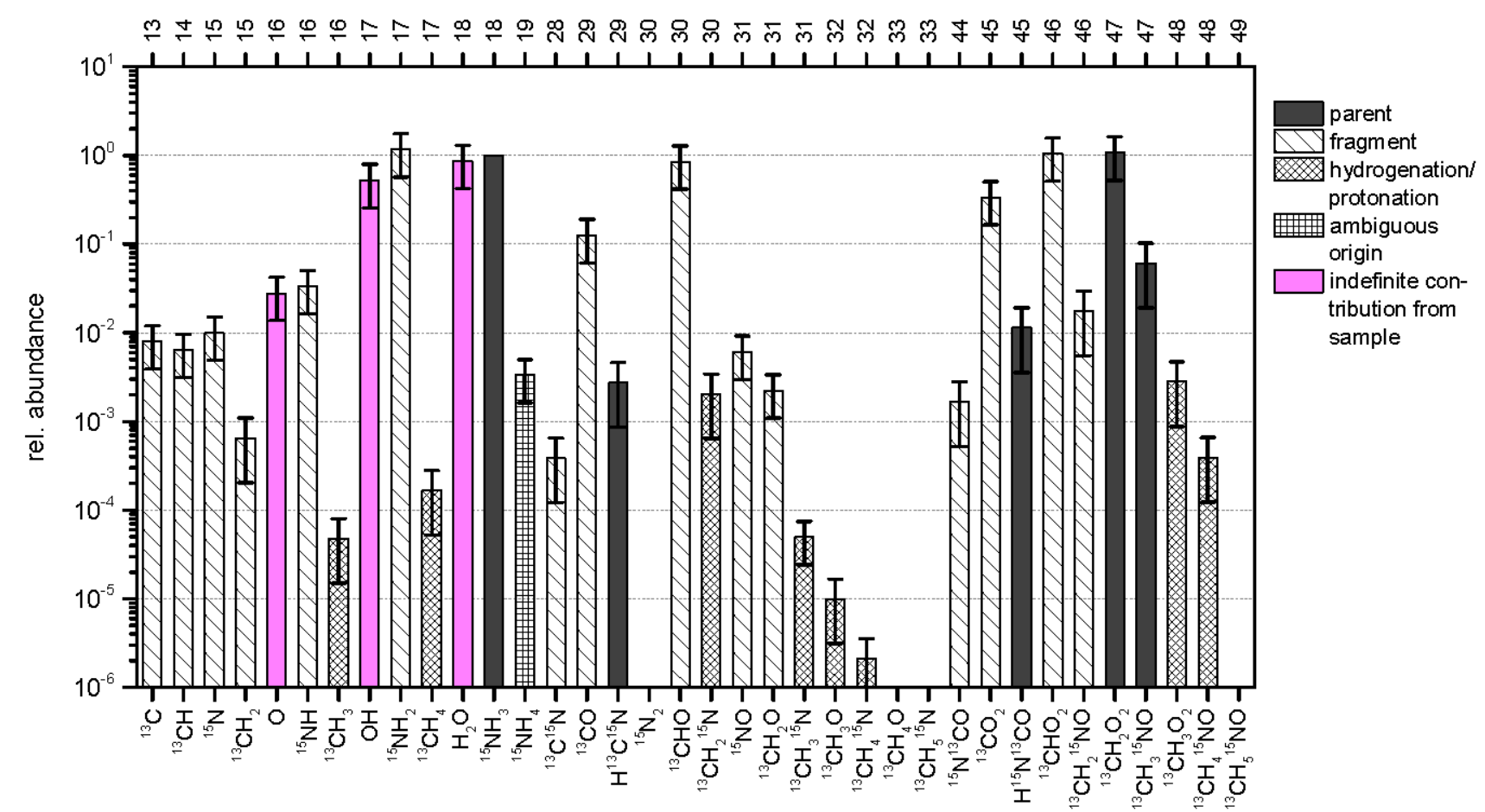

Figure 5. Abundance of ${ }^{15} \mathrm{NH}_{4} \mathrm{OO}^{13} \mathrm{CH}$-related species, relative to ${ }^{15} \mathrm{NH}_{3}$. The top scale specifies the integer masses of the species given in the bottom scale. If chemical formulae are not written in the standard Hill notation, the most probable isomer is indicated. The species were observed upon sublimation of the salt at room temperature and $\mathrm{p} 1=(2.1 \pm 0.3)^{\star} 10^{-7} \mathrm{mbar}$ in the ionization chamber. The exact values, including error estimates for the observed corrected peak areas, are listed in Table S3.

Relevant qualitative information on the physico-chemical processes occurring during the sublimation of ammonium formate can be extracted from the data in Figure 5. Major species from the sublimation/decomposition of the salt are ${ }^{15} \mathrm{NH}_{3}$ and $\mathrm{H}^{13} \mathrm{COOH}$, as expected. As was the case with our experiments on ammonium chloride, ${ }^{15} \mathrm{NH}_{4}$ is observed, but in even greater abundance and is likely the product of proton back-transfer reactions within the co-desorbing ammonia and formic acid. To enter the ionization region of DFMS, an associated complex must be neutral and possess a sufficiently long life time. Details were discussed in the context of the 
ammonium chloride experiments in subsection 3.1. The parent species in this instance, ${ }^{15} \mathrm{NH}_{4} \mathrm{OO}^{13} \mathrm{CH}$ at $\mathrm{m} / \mathrm{z}=65.0319$, was again not observed. However, several organic species which originate from a reaction between ammonia and formic acid were detected in abundance. Due to the low pressures used in the experiments (not higher than $1 * 10^{-4}$ mbar, even in the sample volume in front of the leak valve), the most probable formation pathway for the observed molecular species would be via pseudo-intramolecular chemical reactions during or after desorption. Our data provides evidence for the presence of hydrogen (iso)cyanide $\mathrm{H}^{13} \mathrm{C}^{15} \mathrm{~N}$ (or $\mathrm{H}^{15} \mathrm{~N}^{13} \mathrm{C}$ ) at $\mathrm{m} / \mathrm{z}=29.0108$, (iso)cyanic acid $\mathrm{HO}^{13} \mathrm{C}^{15} \mathrm{~N}$ (or $\mathrm{H}^{15} \mathrm{~N}^{13} \mathrm{CO}$ ) at $\mathrm{m} / \mathrm{z}=45.0057$, and formamide (or nitroso-methane) ${ }^{13} \mathrm{CH}_{3}{ }^{15} \mathrm{NO}$ at $\mathrm{m} / \mathrm{z}=47.0213$. The corresponding mass spectra are presented in Figure $6(\mathrm{a}-\mathrm{c})$ and discussed after a note on the general problem of MS experiments not allowing the distinction of isomers (structural and spatial). Based on literature cited in the following, we address this experimental limitation for the specific case of the three species just mentioned. Hydrogen isocyanide is claimed to be a minor tautomer of hydrogen cyanide at room temperature that becomes relevant at low temperatures such as in interstellar clouds. ${ }^{33}$ Older reports mention an energy barrier to the tautomerization reaction of about 48 $\mathrm{kcal} / \mathrm{mol}$ based on ab initio calculations. ${ }^{34}$ Literature on isocyanic acid reports its tautomer, cyanic acid, to come from the low temperature photolysis of isocyanic acid-containing solid matrices. ${ }^{35}$ We consider this of minor relevance to our experimental setting. As fulminic acid is an unstable isomer of isocyanic acid, the majority (if not all) of our HNCO-labelled signal is probably due to isocyanic acid. In the case of formamide, there is one stable isomer to be addressed, namely, nitroso-methane. According to NIST (NIST MS no. 76), its molecular ion peak has about $70 \%$ r.i., while the main peak is due to NO. Comparing their respective signals as listed in Table S3 in the supplementary material, the ${ }^{15} \mathrm{NO}$ signal is about $75 \%$ of the ${ }^{13} \mathrm{CH}_{3}{ }^{15} \mathrm{NO}$ signal, an indication that formamide is the most relevant isomer. Fragmentation of ${ }^{15} \mathrm{NO}-$ bearing species could also have contributed to the observed ${ }^{15} \mathrm{NO}$ signal. 

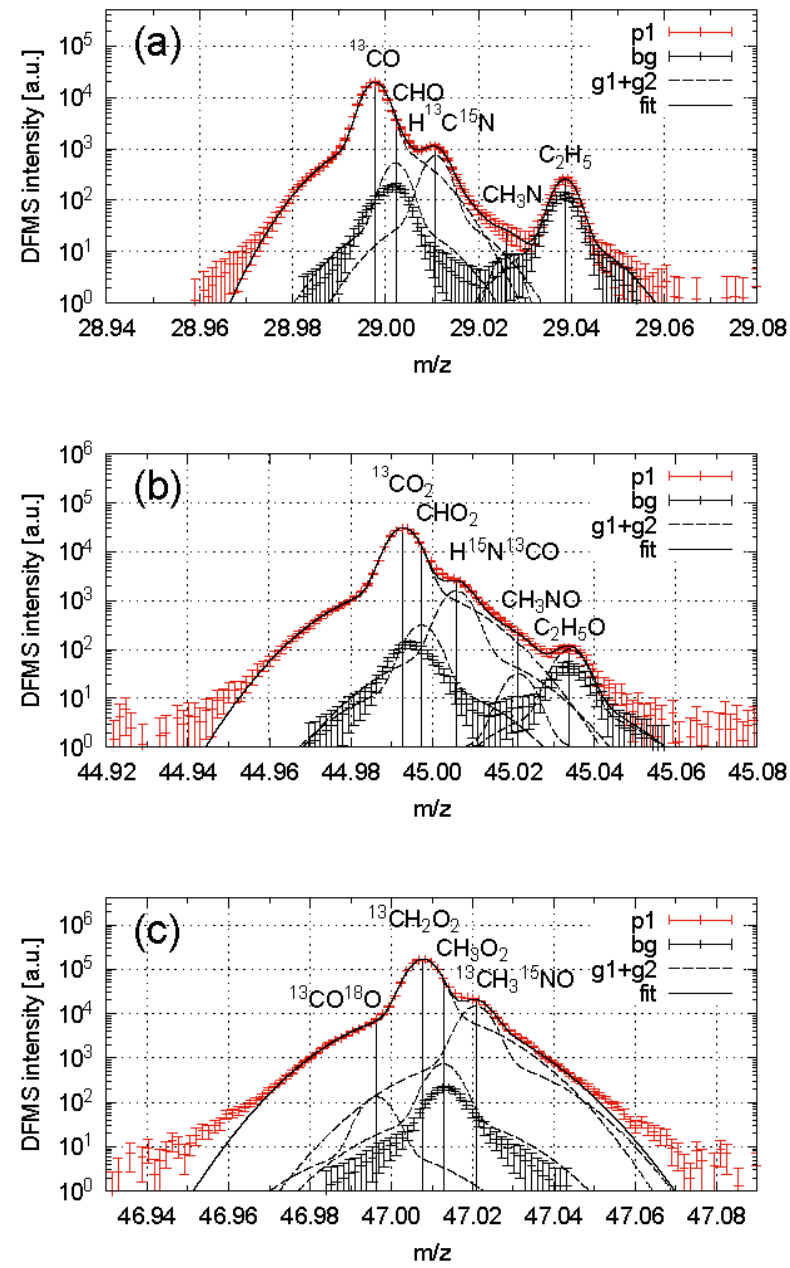

Figure 6. Plots of the p1 mass spectra of ${ }^{13} \mathrm{C}^{15} \mathrm{~N}$-ammonium formate (red) and the background signal (black) when the leak valve was still closed. The mass spectra exhibit signals at the expected positions of (a) $\mathrm{H}^{13} \mathrm{C}^{15} \mathrm{~N}$ (or $\mathrm{H}^{15} \mathrm{~N}^{13} \mathrm{C}$ ) at $\mathrm{m} / \mathrm{z}=29.0108$, (b) $\mathrm{H}^{15} \mathrm{~N}^{13} \mathrm{CO}$ (or $\mathrm{HO}^{13} \mathrm{C}^{15} \mathrm{~N}$ ) at $\mathrm{m} / \mathrm{z}=45.0057$, and (c) ${ }^{13} \mathrm{CH}_{3}{ }^{15} \mathrm{NO}$ at $\mathrm{m} / \mathrm{z}=47.0213$. Background species include $\mathrm{C}_{2} \mathrm{H}_{5}$, $\mathrm{CH}_{3} \mathrm{NO}, \mathrm{C}_{2} \mathrm{H}_{5} \mathrm{O}, \mathrm{CH}_{3} \mathrm{O}_{2}$ etc.

The observation of the three parent molecules reported in the previous paragraph and shown in Figure 6 is consistent with theoretical calculations. Literature gives evidence that the formation of formamide from co-desorbing ammonia and formic acid could pave the way for the formation of hydrogen (iso)cyanide as well as isocyanic acid. For this very reason, formamide 
has been considered an active key precursor in the prebiotic chemistry of the early Earth and its investigation is of broad interest to various fields of research, from astrochemistry to experimental astrophysics and astronomy. It has been shown by Oie et al. (1982) that formamide (and water) can be obtained from formic acid and ammonia via an $\mathrm{S}_{\mathrm{N} 2}$ reaction. ${ }^{36}$ Based on semi-empirical and ab initio molecular orbital methods, the authors found that stepwise and concerted reaction mechanisms are fairly competitive. The formation of hydrogen (iso)cyanide and (iso)cyanic acid from the decomposition of formamide is widely discussed in the literature and has been investigated from a theoretical perspective by Nguyen et al. (2001, 2013). ${ }^{37-38}$ Applying the coupled-cluster theory with energies extrapolated to the complete basis set limit, the authors constructed a formamide potential energy surface and used the RiceRampserger-Kassel-Markus theory to systematically examine possible decomposition channels. Three unimolecular decomposition reactions of formamide (dehydrogenation into $\mathrm{HNCO}+\mathrm{H}_{2}$, decarbonylation into $\mathrm{NH}_{3}+\mathrm{CO}$, and dehydration into $\mathrm{HCN} / \mathrm{HNC}+\mathrm{H}_{2} \mathrm{O}$ ) were found which appeared to possess comparable energy barriers in the range of $73-78 \mathrm{kcal} / \mathrm{mol}$. The (self-)catalytic role of water is addressed in detail by the same authors, especially in Ref. 38. The formic acid molecule is also known to undergo decarboxylation reactions (into $\mathrm{H}_{2}+\mathrm{CO}_{2}$ ) and dehydration reactions (into $\mathrm{H}_{2} \mathrm{O}+\mathrm{CO}$ ) with comparable energy barriers. This was investigated theoretically several decades ago and reported by Refs. 21-22. All of these decomposition products were detected in abundance in our data with the exception of $\mathrm{H}_{2}$, which lies outside of the accessible mass range of DFMS. According to NIST, $\mathrm{CO}_{2}$ is a $15 \%$ r.i. fragment of formic acid. We observed about $30 \%$ r.i. based on the corrected peak areas from Table S3 in the supplementary material. CO is a 13\% r.i. fragment of formic acid, we observed $12 \%$ r.i. Even though quantification of our data appears difficult for the reasons explained, these numbers seem to indicate a minor parent contribution from ${ }^{13} \mathrm{CO}_{2}$ (but not from ${ }^{13} \mathrm{CO}$ ). The intensity of the observed water signal is difficult to analyze, as indicated in Figure 5 by the notion 
'indefinite contribution from sample', as the sample was prepared from an aqueous solution. Due to heavy sublimation already at room temperature, it was not possible to remove residual water quantitatively. Hence, a probably great amount of the observed water is not actually produced by the various relevant water-producing reactions (formic acid dehydration, formamide formation, formamide dehydration), but is due to the wet sample.

The data for the ${ }^{13} \mathrm{C}^{15} \mathrm{~N}$-isotopologue of ammonium formate shows no evidence of several other small organic molecules, which could in principle form during the sublimation process, though most of them would require more complex reaction pathways. No signal of any appreciable intensity is seen at the molecular ion positions of methanol (NIST MS no. $229809:{ }^{13} \mathrm{CH}_{4} \mathrm{O}, \mathrm{m} / \mathrm{z}$ $=33, \sim 75 \%$ r.i.), methylamine (NIST MS no. $228024:{ }^{13} \mathrm{CH}_{5}{ }^{15} \mathrm{~N}, \mathrm{~m} / \mathrm{z}=33, \sim 65 \%$ r.i.), hydroxylamine (NIST MS no. $228320:{ }^{15} \mathrm{NOH}_{3}, \mathrm{~m} / \mathrm{z}=34,100 \%$ r.i.), acetonitrile (NIST MS no. 228221: ${ }^{13} \mathrm{C}_{2} \mathrm{H}_{3}{ }^{15} \mathrm{~N}, \mathrm{~m} / \mathrm{z}=44,100 \%$ r.i.), ethylamine (NIST MS no. $71:{ }^{13} \mathrm{C}_{2} \mathrm{H}_{7}{ }^{15} \mathrm{~N}, \mathrm{~m} / \mathrm{z}=48$, $\sim 20 \%$ r.i.), and O-methyl-hydroxylamine (NIST MS no. $230263:{ }^{13} \mathrm{CH}_{5}{ }^{15} \mathrm{NO}, \mathrm{m} / \mathrm{z}=49,100 \%$ r.i.). While the molecular ion signal of methylamine is not observed, a very minor peak is observed at the position of methylamine- $\mathrm{H}\left({ }^{13} \mathrm{CH}_{4}{ }^{15} \mathrm{~N}\right)$, a stronger one at the position of methylamine-2H $\left({ }^{13} \mathrm{CH}_{3}{ }^{15} \mathrm{~N}\right)$, and an even greater one at the position of methylamine-3H $\left({ }^{13} \mathrm{CH}_{2}{ }^{15} \mathrm{~N}\right)$. This pattern, of intensity monotonously decreasing with the increasing number of $\mathrm{H}$-atoms in the molecule, differs considerably from the NIST standard pattern for methylamine, suggesting an origin other than El fragmentation. Hydrogen atoms, released by chemical reactions of the sublimating salt and by El fragmentation, could have acted on the HCN (or $\mathrm{HNC}$ ) molecule as a hydrogenating agent. Hydrogenation of a solid HCN target struck by warm $\mathrm{H}$-atoms produced in a $\mathrm{H}_{2}$ plasma source was performed by Theulé et al. (2011), who reported the formation of methylamine. ${ }^{39}$ The proposed intermediate species $\mathrm{CH}_{2} \mathrm{NH}$ (methanimine) has also been shown to form methylamine when bombarded with $\mathrm{H}$-atoms. As hydrogenation products are monitored only in temperature-programmed desorption experiments (desorption 
starting above $100 \mathrm{~K}$ ) with a mass spectrometer, it is not clear whether methylamine forms in the solid phase on the $15 \mathrm{~K}$ substrate, or if the reactions actually occur at some higher temperature. In contrast to Theulé et al., who only observed the fully hydrogenated methylamine, we observed a signal at the expected position of methanimine and at methanimine $+\mathrm{H}$, but we did not observe a signal at the molecular ion position of methylamine. From the NIST standard mass spectrum (NIST MS no. 228024), the molecular ion signal of methylamine is expected to be less abundant than methanimine+H (or methylamine- $\mathrm{H}$ ) and therefore below the limits of detection in our experiments. Further experiments would be required to investigate the hydrogenating capacity of sublimating ammonium salt. A similar situation is observed for formamide. As there is no signal at the position of O-methylhydroxylamine $\left({ }^{13} \mathrm{CH}_{5}{ }^{15} \mathrm{NO}\right)$, the signal at the position of ${ }^{13} \mathrm{CH}_{4}{ }^{15} \mathrm{NO}$ is attributed to formamide $+\mathrm{H}$. In addition to hydrogenation, the protonation of species could also have occurred. For instance, the formic acid fragment species ${ }^{13} \mathrm{COH}_{2}$ is expected to yield the ${ }^{13} \mathrm{COH}_{3}{ }^{+}$cation. Similarly, protonation of formic acid would yield $\mathrm{H}^{13} \mathrm{COOH}_{2}{ }^{+}$, protonation of ${ }^{15} \mathrm{NH}_{3}$ would yield ${ }^{15} \mathrm{NH}_{4}{ }^{+}$, and protonation of $\mathrm{H}_{2} \mathrm{O}$ would yield $\mathrm{H}_{3} \mathrm{O}^{+}$. All of these species were detected (see Table S3 in the supplementary material). However, once a species is protonated, the positive charge would hinder additional protonation and also prevent the protonated species from entering the ionization chamber (if the protonation reaction occurred in the sample volume). This is very different for the hydrogenation reaction. Finally, the formation of acetonitrile and ethylamine requires the involvement of formic acid clusters. Though gas phase formic acid dimers have been widely investigated as molecular cluster model systems via both spectroscopic and ab initio modelling methods (e.g. Refs. 40-42 and literature cited therein), our high-resolution El-MS data of ${ }^{14} \mathrm{C}^{15} \mathrm{~N}$-ammonium formate (up to $\mathrm{m} / \mathrm{z}=100$ ) contains neither direct nor indirect evidence for the dimerization of formic acid. 


\section{Summary and Conclusions}

In our high-resolution neutral gas mode El-MS experiments on two prototypic ammonium salts, we observed complex mass spectra resulting from a mixture of sublimation, decomposition, and fragmentation processes. Our experiments, by design, did not allow for full clarification of the involved formation pathways/mechanism/life times of all the observed species. Nonetheless, we were able to successfully extract qualitative fingerprints (for comparison with in situ space El-MS data such as produced by e.g. ROSINA/DFMS onboard the European Space Agency's Rosetta spacecraft) of sublimating ammonium chloride and ammonium formate. In summary, we establish tentative chemical networks, sketched in Figure 7, which are compatible with both our data and the theoretical literature we discussed and reviewed up to this point.

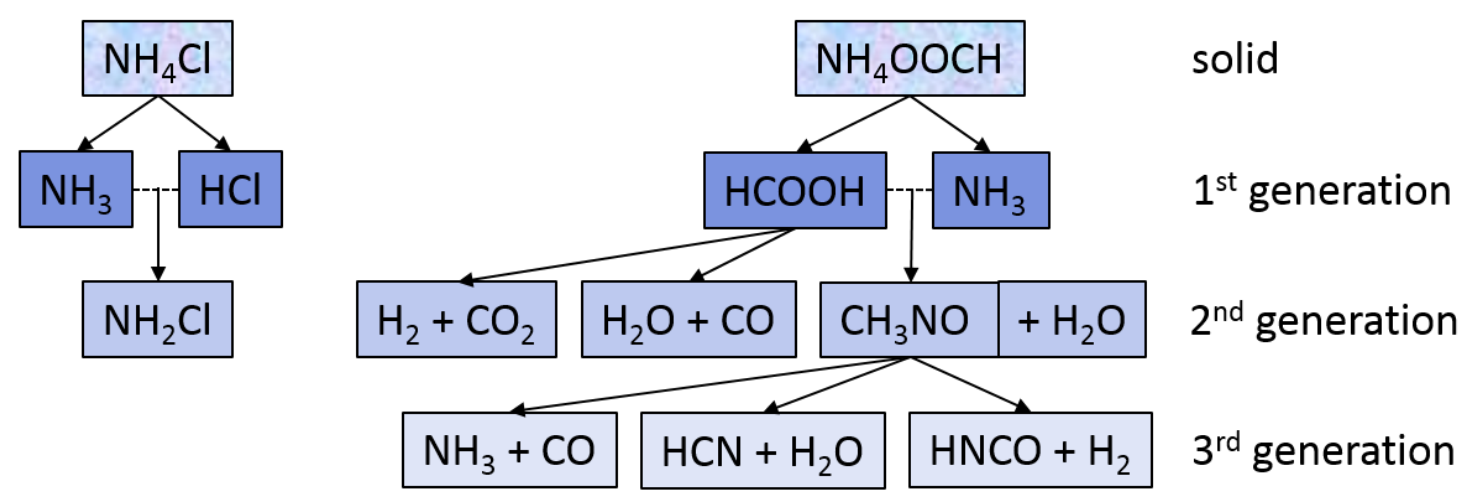

Figure 7. Tentative chemical networks compatible with our data and the reviewed theoretical literature: Both ammonium salts, ammonium chloride (left) and ammonium formate (right), seem to form traces of secondary amide species (chloramide and formamide, respectively) upon sublimation, besides from the primary decomposition products $\mathrm{NH}_{3}$ and the corresponding acid. Formamide is known to decompose via three energetically comparable reaction channels to form the specified ternary molecular species. Only the most probably isomers are indicated. 
From Figure 7 it becomes obvious that the simultaneous observation of abundant and correlated ammonia and hydrochloric acid (and their isotopologues and fragments) alongside traces of $\mathrm{NH}_{4}$ and $\mathrm{NH}_{2} \mathrm{Cl}$ (and their isotopologues and fragments) strongly indicates the presence of sublimating ammonium chloride. $\mathrm{NH}_{2} \mathrm{Cl}$ is most likely formed in a pseudointramolecular reaction between $\mathrm{NH}_{3}$ and $\mathrm{HCl}$ when these two molecules are in a state of association during sublimation. An associated and probably molecular complex $\mathrm{NH}_{3} \ldots \mathrm{HCl}$ has been proposed in a recent theoretical study by Zhu et al. (2007). ${ }^{13}$ The authors find that dissociation following co-desorption is fast. $\mathrm{NH}_{2} \mathrm{Cl}$ shows the same pressure/temperature dependence as the two main species, $\mathrm{NH}_{3}$ and $\mathrm{HCl}$, and its observation was reproducible with both investigated isotopologues of ammonium chloride. Confirming the report by Goldfinger and Verhaegen from $1969,{ }^{15}$ we did not directly observe the signal of the parent species $\mathrm{NH}_{4} \mathrm{Cl}$ within detection limits but the signal of $\mathrm{NH}_{4}$ (and isotopologues). However, other than these authors do, we do not readily infer from that the existence of an associated gas phase complex $\mathrm{NH}_{3} \ldots \mathrm{HCl}$ (or $\mathrm{NH}_{4}^{+} \ldots \mathrm{Cl}^{\text {) }}$ ) with a long enough life time to reach the our ionization chamber, because the observation of various protonated/hydrogenated species in our experiments with ${ }^{13} \mathrm{C}^{15} \mathrm{~N}$-ammonium proposes an alternative route of formation of the ammonium ion. Based on our experimental possibilities, we cannot differentiate between the two scenarios.

Ammonium formate shows a more complex signature. The occurrence of abundant and correlated formic acid and ammonia alongside with traces of secondary and ternary species (formamide, hydrogen (iso)cyanide, (iso)cyanic acid) indicates the presence of sublimating ammonium formate. Analogously to ammonium chloride, no signal of the parent compound is observed within limits of detection. Only analysis of the rare isotope-enriched ${ }^{13} \mathrm{C}^{15} \mathrm{~N}$ ammonium formate allowed us to clearly distinguish the group of species formed during the sublimation process from the group of species formed artifactually. 
Our results qualitatively agree with the referenced AIST/NIST standard fragmentation patterns, as well as with results from previous experimental work by Goldfinger and Verhaegen in $1969 .{ }^{15}$ Observed deviations probably result from different experimental set-ups, e.g. regarding ionization energies or sample inlet systems and temperatures. The AIST/NIST standard spectrum of ammonium chloride was measured with a heated reservoir inlet system and therefore similar sublimation conditions are met. Goldfinger and Verhaegen instead were using effusion from a Knudsen cell at low temperatures, adding probably the least possible amount of thermal energy to the sublimation. Generally, the experimental method of El-MS does not readily discriminate between processes occurring during sublimation and processes occurring during fragmentation. The combination of EI-MS with spectroscopic techniques has the potential to better resolve encountered ambiguities. Also computational modelling of these more complex chemical gas phase systems could provide further valuable insights.

\section{Supplementary Material Description}

-Table S1: Reference EI mass spectrum of ammonium chloride taken from the NIST/AIST data bases.

-Figure S1: Scaled schematic drawings showing the experimental set-up for the ammonium chloride as well as the ammonium formate measurements.

-Figure S2: X-ray powder diffraction pattern of the synthesized ${ }^{13} \mathrm{C}^{15} \mathrm{~N}$-ammonium formate.

-Table S2: Summary of the extracted relative abundances of the relevant species observed in the ammonium chloride experiments.

-Figure S3: Fits of the ammonium ion signal on the m18 mass spectrum including its pressure dependence. 
-Table S3: Summary of the extracted relative abundances of the species observed in the ${ }^{13} \mathrm{C}^{15} \mathrm{~N}$-ammonium formate experiments.

\section{Acknowledgments}

For the sample material and support with the sample preparation we thank D. Biner, B. Frey, PD Dr. K. Krämer, C. A. Melendez Becerra, and Prof. P. Renaud from the Department of Chemistry and Biochemistry at the University of Bern. The financial support by the SNSF (project grant no. 200020_182418 and Eccellenza Professorial Fellowship no. PCEFP2_181158) is gratefully acknowledged. 


\section{References}

${ }^{1}$ Sefton-Nash, E; Catling, D. C; Wood, S. E.; Grindrod, P. M.; Teanby, N. A. Topographic, Spectral and Thermal Inertia Analysis of Interior Layered Deposits in Iani Chaos, Mars. Icarus 2012, 221, 20-42.

2 King, T. V.; Clark, R. N.; Calvin, W. M.; Sherman, D. M.; Brown, R. H. Evidence for Ammonium-Bearing Minerals on Ceres. Science 1992, 255 (5051), 1551-1553.

${ }^{3}$ DeSanctis, M. C.; Raponi, A.; Ammannito, E.; Ciarniello, M.; Toplis, M. J.; McSween, H. Y.; Castillo-Rogez, J. C.; Ehlmann, B. L.; Carrozzo, F. G.; Marchi, S. et al. Bright Carbonate Deposits as Evidence of Aqueous Alteration on (1) Ceres. Nature 2016, 536, 54-58.

${ }^{4}$ Quirico, E.; Moroz, L. V.; Schmitt, B.; Arnold, G.; Faure, M.; Beck, P.; Bonal, L.; Ciarniello, M.; Capaccioni, F.; Filaccione, G. et al. Refractory and Semi-Volatile Organics at the Surface of Comet 67P/Churyumov-Gerasimenko: Insights from the VIRTIS/Rosetta Imaging Spectrometer Icarus 2016, 272, 32-47.

${ }^{5}$ Altwegg, K.; Balsiger, H.; Berthelier, J. J.; Bieler, A.; Calmonte, U.; Fuselier, S. A.; Goesmann, F.; Gasc, S.; Gombosi, T. I.; Le Roy, L. et al. Organics in Comet 67P - A First Comparative Analysis of Mass Spectra from ROSINA-DFMS, COSAC and Ptolemy. Mon. Notices Royal Astron. Soc. 2017, 469, 130-141. 
${ }^{6}$ Gmelins Handbuch der Anorganischen Chemie, Gmelin-Institut in Clausthal-Zellerfeld (Editorin-Chief: Deutsche Chemische Gesellschaft); Verlag Chemie GMBH: Berlin, 1936, ed. 8, no. 23, $150-165$.

${ }^{7}$ Braune, H.; Knoke, S. Die Dissoziation des Salmiakdampfes. Z. Phys. Chem. 1928, 135, 59.

8 Smits, A.; deLange W. Determination of the Pressure and Density of Moist, Saturated Ammonium Chloride Vapor. J. Chem. Soc. 1928, 2944-2952.

${ }^{9}$ Baker, H. B. Influence of Moisture on Chemical Change. J. Chem. Soc. 1894, 65, 611.

10 Smith, A.; Lombard, R. H. The Densities and Degrees of Dissociation of the Saturated Vapors of Ammonium Halides and the Related Thermal Data. J. Am. Soc. 1915, 37, 38-70.

${ }^{11}$ Rodebush, W. H.; Michalek, J. C. The Vapor Pressure and the Vapor Density of Intensively Dried Ammonium Chloride. J. Am. Chem. Soc. 1929, 51, 748.

${ }^{12}$ Clementi, E. Study of the Electronic Structure of Molecules. II. Wavefunctions for the $\mathrm{NH}_{3}+$ $\mathrm{HCl}->\mathrm{NH}_{4} \mathrm{Cl}$ Reaction. J. Chem. Phys. 1967, 46, 3851.

${ }^{13}$ Zhu, R. S.; Wang, J. H.; Lin, M. C. Sublimation of Ammonium Salts: a Mechanism Revealed by a First-Principles Study of the $\mathrm{NH}_{4} \mathrm{Cl}$ System. J. Phys. Chem. C 2007, 111, 13831.

14 Knacke, O.; Stranski, I. N.; Wolff, G. Z. Zur Theorie der Verdampfungsgeschwindigkeit. Z. Phys. Chem. 1951, 198157. 
${ }^{15}$ Goldfinger, P.; Verhaegen, G. Stability of the Gaseous Ammonium Chloride Molecule. J. Chem. Phys. 1969, 50 (3), 1467.

${ }^{16}$ Clementi, E.; Gayles, J. N. Study of the Electronic Structure of Molecules. VII. Inner and Outer Complex in the $\mathrm{NH}_{4} \mathrm{Cl}$ Formation from $\mathrm{NH}_{3}$ and $\mathrm{HCl}$. J. Chem. Phys. 1967, 47, 3837.

${ }^{17}$ NIST Mass Spectrometry Data Center (Director: Wallace, E. W.). Mass Spectra in NIST Chemistry WebBook, NIST Standard Reference Database Number 69 (Eds.: P.J. Linstrom, P. J.; Mallard, W. G.); National Institute of Standards and Technology, Gaithersburg MD, USA (accessed April 9, 2019).

${ }^{18}$ SDBSWeb: https://sdbs.db.aist.go.jp; National Institute of Advanced Industrial Science and Technology (accessed April 9, 2019).

19 Gmelins Handbuch der Anorganischen Chemie, Gmelin-Institut in Clausthal-Zellerfeld (Editor-in-Chief: Deutsche Chemische Gesellschaft); Verlag Chemie GMBH: Berlin, 1936, ed. 8, no. $23,388-392$.

20 Safety Data Sheet (ammonium acetate, product number 73594, CAS number 631-61-8); Supelco/Sigma-Aldrich Chemie GmbH, 9470 Buchs, Switzerland (April 2019, version 6.1).

${ }^{21}$ Goddard, J. D.; Yamaguchi, Y.; Schaefer III, H. F. The Decarboxylation and Dehydration Reactions of Monomeric Formic Acid. J. Chem. Phys. 1992, 96 (2), 1158. 
${ }^{22}$ Francisco, J. S. A Comprehensive Theoretical Examination of Primary Dissociation Pathways of Formic Acid. J. Chem. Phys. 1992, 96 (2), 1167.

${ }^{23}$ Dello Russo, N.; Kawakita, H.; Vervack Jr., R. J.; Weaver, H. A. Emerging Trends and a Comet Taxonomy Based on the Volatile Chemistry Measured in Thirty Comets with HighResolution Infrared Spectroscopy between 1997 and 2013. Icarus 2016, 278, 301-332.

${ }^{24}$ Mattauch, J.; Herzog, R. F. K. Über einen neuen Massenspektrographen. Z. Physik 1934, 9 786-795.

${ }^{25}$ Balsiger, H.; Altwegg, K.; Bochsler, P.; Eberhardt, P.; Fischer, J.; Graf, S.; Jäckel, A.; Kopp, E.; Langer, U.; Mildner, M. et al. Rosina - Rosetta Orbiter Spectrometer for Ion and Neutral Analysis. Space Science Reviews 2007, 128, 745-801.

26 Summers, R. L. NASA Technical Note TND-5285; National Aeronautics and Space Administration, Washington DC, USA: 1969.

${ }^{27}$ Zawadzki, M. Electron-Impact Ionization Cross Section of Formic Acid. Eur. Phys. J. D 2018, $72,12$.

${ }^{28}$ Kim, Y.-K.; Irikura, K .K.; Rudd, M. E.; Ali, M. A.; Stone, P. M.; Chang, J.; Coursey, J. S.; Dragoset, R. A.; Kishore, A. R.; Olsen, K. J. et al. Electron-Impact Cross Sections for Ionization and Excitation Database, NIST Standard Reference Database 107 (Last Update to Data Content: August 2004). 
Granville-Phillips Stabil-Ion Vacuum Gauge Spacification Sheet; MKS Instruments Inc., Granville-Phillips Division, 6450 Dry Creek Parkway, Longmont CO, USA (2014-2018).

${ }^{30}$ Meija, J.; Coplen, T. B.; Berglund, M.; Brand, W. A.; De Bièvre, P.; Gröning, M.; Holden, N. E.; Irrgeher, J.; Loss, R. D.; Walczyk, T. et al. Atomic Weights of the Elements 2013 (IUPAC Technical Report). Pure Appl. Chem. 2016, 88 (3), 265-291.

${ }^{31}$ Schuhmann, M; Altwegg, K; Balsiger, H.; Berthelier, J.-J.; De Keyser, J.; Fiethe, B.; Fuselier, S. A.; Gasc, S.; Gombosi, T. I.; Hänni, N. et al. Aliphatic and Aromatic Hydrocarbons in Comet67P/Churyumov-Gerasimenko Seen by ROSINA. Astron. Astrophys. 2019, in press.

32 Schuhmann, M; Altwegg, K; Balsiger, H.; Berthelier, J.-J.; De Keyser, J.; Fiethe, B.; Fuselier, S. A.; Gasc, S.; Gombosi, T. I.; Hänni, N. et al. CHO-Bearing Molecules in Comet 67P/Churyumov-Gerasimenko. ACS Earth Sp. Chem. 2019, submitted.

${ }^{33}$ Hirota T.; Yamamoto, S.; Mikami, H.; Ohishi, M. Abundances of HCN and HNC in Dark Cloud Cores. Astrophysical Journal 1998, 503 (2), 717-728.

34 Pearson, K.; Schaefer III, H. F.; Wahlgren, U. Potential Energy Surface for the Model Unimolecular Reaction HNC -> HCN. J. Chem. Phys. 1975, 62, 350.

35 Jacox, M. E.; Milligan, D. E. Low-Temperature Infrared Study of Intermediates in the Photolysis of HNCO and DNCO. Journal of Chemical Physics 1964, 40 (9), 2457-2460. 
${ }^{36}$ Oie, T.; Loew, G. H.; Burt, S. K.; Binkley, J. S.; MacElroy, R. D. Quantum Chemical Studies of a Model for Peptide Bond Formation: Formation of Formamide and Water from Ammonia and Formic Acid. J. Am. Chem. Soc. 1982, 104 (23), 6169.

${ }^{37}$ Nguyen, V. S.; Abbott, H. L.; Dawley, M. M.; Orlando, M. T.; Leszczynski, J.; Nguyen, M. T. Theoretical Study of Formamide Decomposition Pathways. J. Phys. Chem. A 2011, 115, 841.

38 Nguyen, V. S.; Orlando, M. T.; Leszczynski, J.; Nguyen M. T. Theoretical Study of the Decomposition of Formamide in the Presence of Water Molecules. J. Phys. Chem. A 2013, $117,2543$.

39 Theulé, P.; Borget, F.; Mispelaer, F.; Danger, G.; Duvernay, F.; Guillemin, J. C.; Chiavassa, T. Hydrogenation of Solid Hydrogen Cyanide $\mathrm{HCN}$ and Methanimine $\mathrm{CH}_{2} \mathrm{NH}$ at Low Temperature. Astronomy and Astrophysics 2011, 534, A64.

${ }^{40}$ Chang, Y.-T.; Yamaguchi, Y.; Miller, W. H.; Schaefer III, H. F. An Analysis of the Infrared and Raman Spectra of the Formic Acid Dimer (HCOOH)2. J. Am. Chem. Soc. 1987, 109 (24), 2745.

${ }^{41}$ Matylitsky, V. V.; Riehn, C.; Gelin, M. F.; Brutschy, B. The Formic Acid Dimer Probed by Time-Resolved Structure Selective Spectroscopy. J. Chem. Phys. 2003, 119, 10553.

${ }^{42}$ Birer, Ö.; Havenith, M. High-Resolution Infrared Spectroscopy of the Formic Acid Dimer. Annu. Rev. Phys. Chem. 2009, 60, 263. 
TOC Graphic

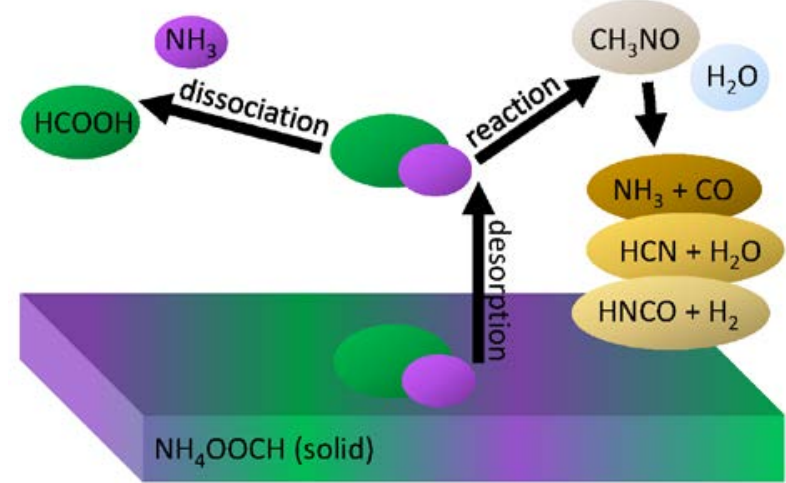




\section{Supplementary Material}

Table S1. Mass spectrum of ammonium chloride (AIST, SDBS No. 1632).

\begin{tabular}{|c|c|c|}
\hline $\mathrm{m} / \mathrm{z}$ & relative intensity & species \\
\hline 14.0 & 0.4 & ${ }^{14} \mathrm{~N}$ \\
\hline 15.0 & 1.3 & ${ }^{14} \mathrm{NH},{ }^{15} \mathrm{~N}$ \\
\hline 16.0 & 44.0 & ${ }^{14} \mathrm{NH}_{2},{ }^{14} \mathrm{ND},{ }^{15} \mathrm{NH}$ \\
\hline 17.0 & 65.4 & ${ }^{14} \mathrm{NH}_{3},{ }^{14} \mathrm{NHD},{ }^{15} \mathrm{NH}_{2},{ }^{15} \mathrm{ND}$ \\
\hline 17.5 & 1.2 & ${ }^{35} \mathrm{Cl}^{++}$ \\
\hline 18.0 & 2.9 & ${ }^{14} \mathrm{NH}_{4},{ }^{14} \mathrm{ND}_{2},{ }^{15} \mathrm{NH}_{3},{ }^{15} \mathrm{NHD}, \mathrm{H}^{35} \mathrm{Cl}^{++}$ \\
\hline 18.5 & 0.4 & ${ }^{37} \mathrm{Cl}^{++}$ \\
\hline 19.0 & 0.1 & $\mathrm{H}^{37} \mathrm{Cl}^{++},{ }^{15} \mathrm{NH}_{4}$ \\
\hline 28.0 & 0.4 & ${ }^{14} \mathrm{~N}_{2}$ \\
\hline 35.0 & 12.6 & ${ }^{35} \mathrm{Cl}$ \\
\hline 36.0 & 100.0 & $\mathrm{H}^{35} \mathrm{Cl}$ \\
\hline 37.0 & 4.6 & ${ }^{37} \mathrm{Cl}, \mathrm{D}^{35} \mathrm{Cl}$ \\
\hline 38.0 & 34.0 & $\mathrm{H}^{37} \mathrm{Cl}$ \\
\hline 39.0 & 0.1 & $\mathrm{D}^{37} \mathrm{Cl}$ \\
\hline
\end{tabular}

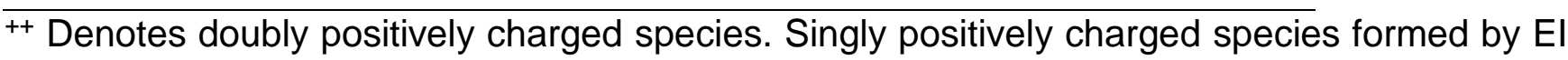
are not specially indicated in this paper. 

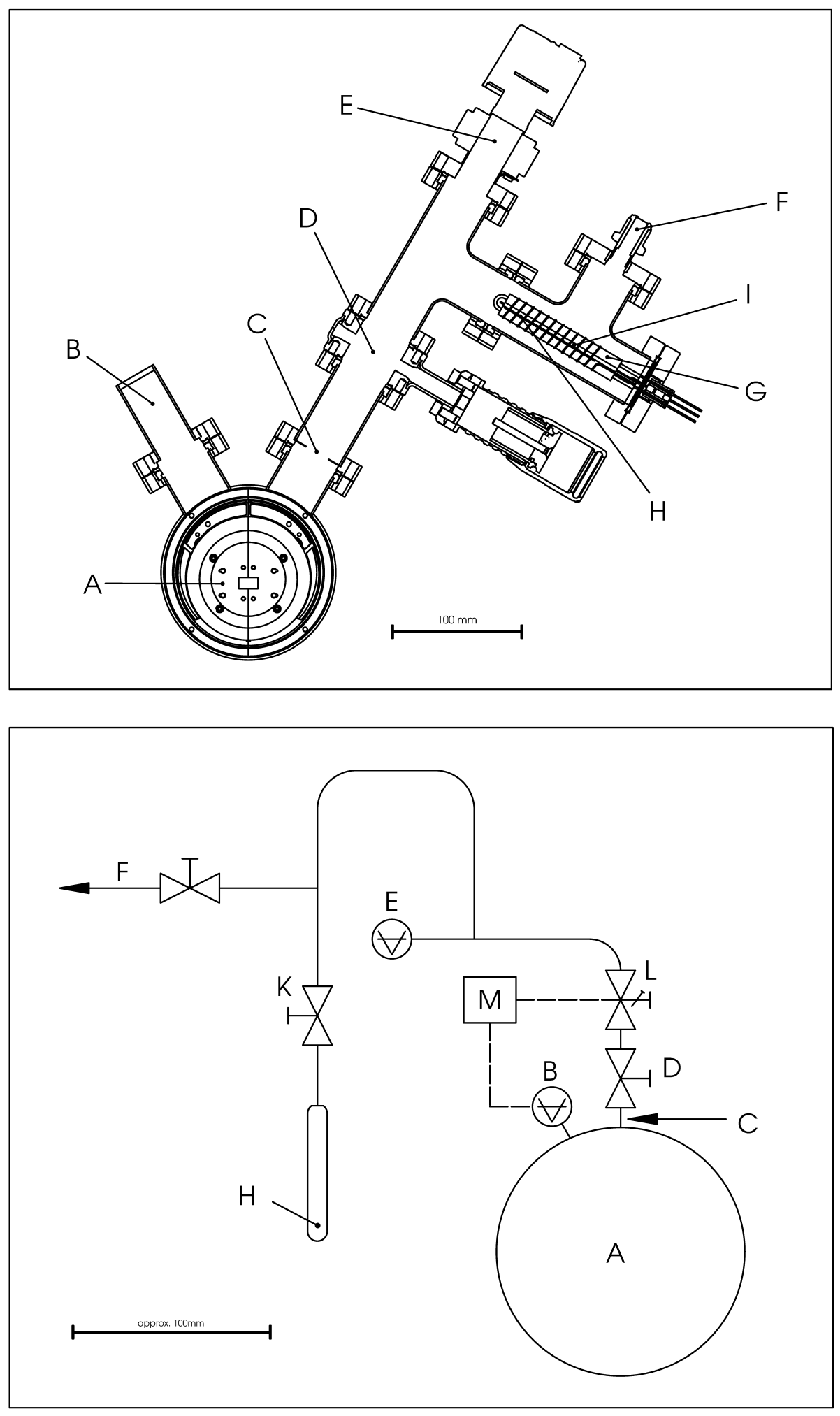

Figure S1. (top) Scaled drawing of the heating chamber (based on two CF-40 T-parts) used for the ammonium chloride experiments. (bottom) Scaled schematic of the gas inlet system for the ammonium formate experiments. Legend: A) DFMS ion source; B) Granville-Phillips pressure gauge; C) aperture (2 cm diameter); D) manual slide valve; E) Pfeiffer vacuum gauge; 
F) connection to pre-pump; G) furnace construction H) sample tube; I) Pt100 resistance temperature detector; K) Swagelok manual valve; L) leak valve; M) Pfeiffer Vacuum RVG050C valve control.

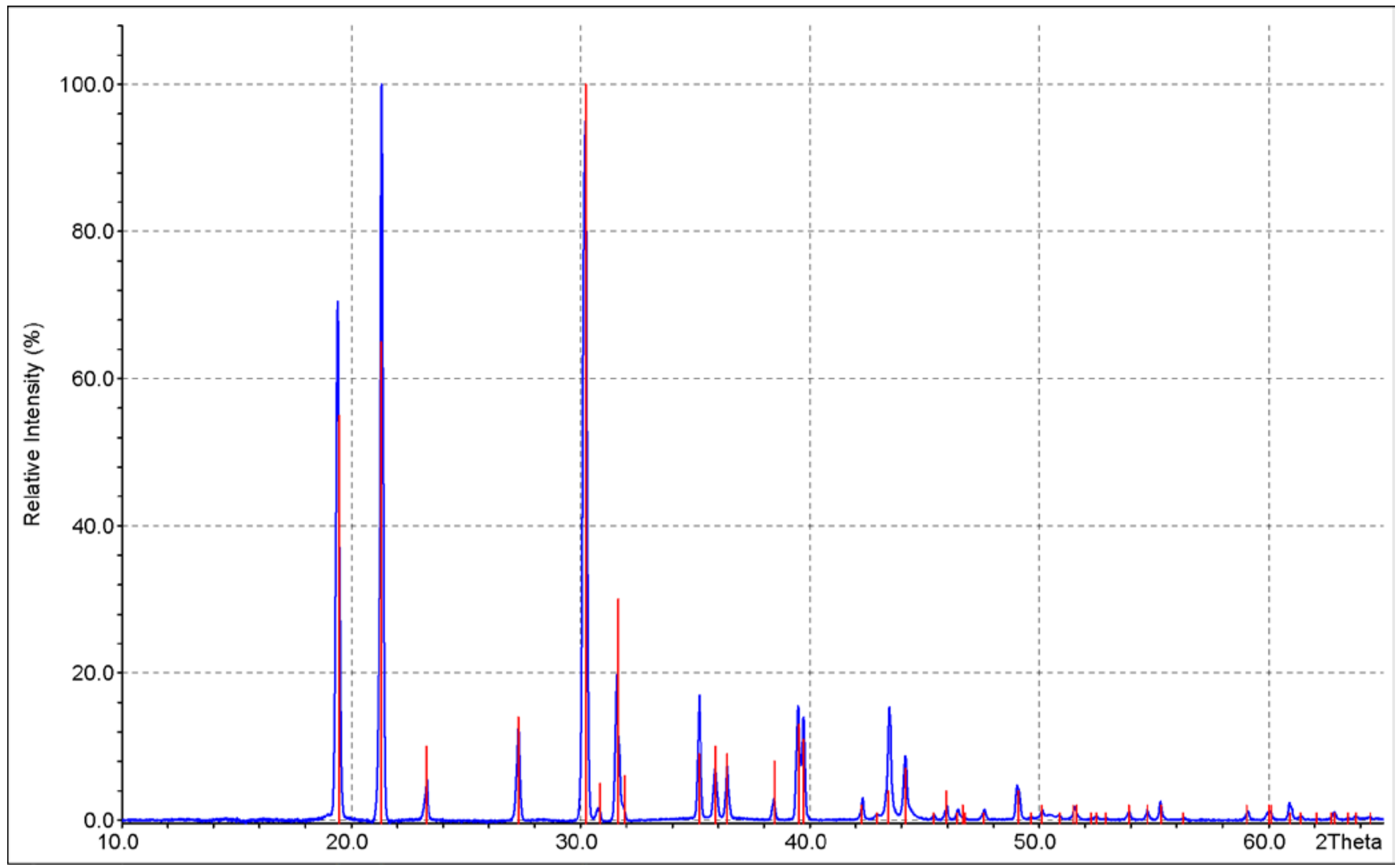

Figure S2. X-ray powder diffraction pattern of ${ }^{13} \mathrm{C}^{15} \mathrm{~N}$-ammonium formate measured on a STOE StadiP powder diffractometer in the reflection geometry. CuKa1 radiation was used and a sample holder closed with Mylar foil to keep the sample dry during the $16 \mathrm{~h}$ of data acquisition. The background due to the Mylar foil was subtracted. From comparing the observed diffraction pattern (blue line) to a reference (red bars) provided by the National Bureau of Standards (Monogr. 1974, 25 (11), 9) and registered in the powder diffraction database PDF2 (entry no. 00-024-1029), the sample is phase pure. Preferred orientation effects are observed. 

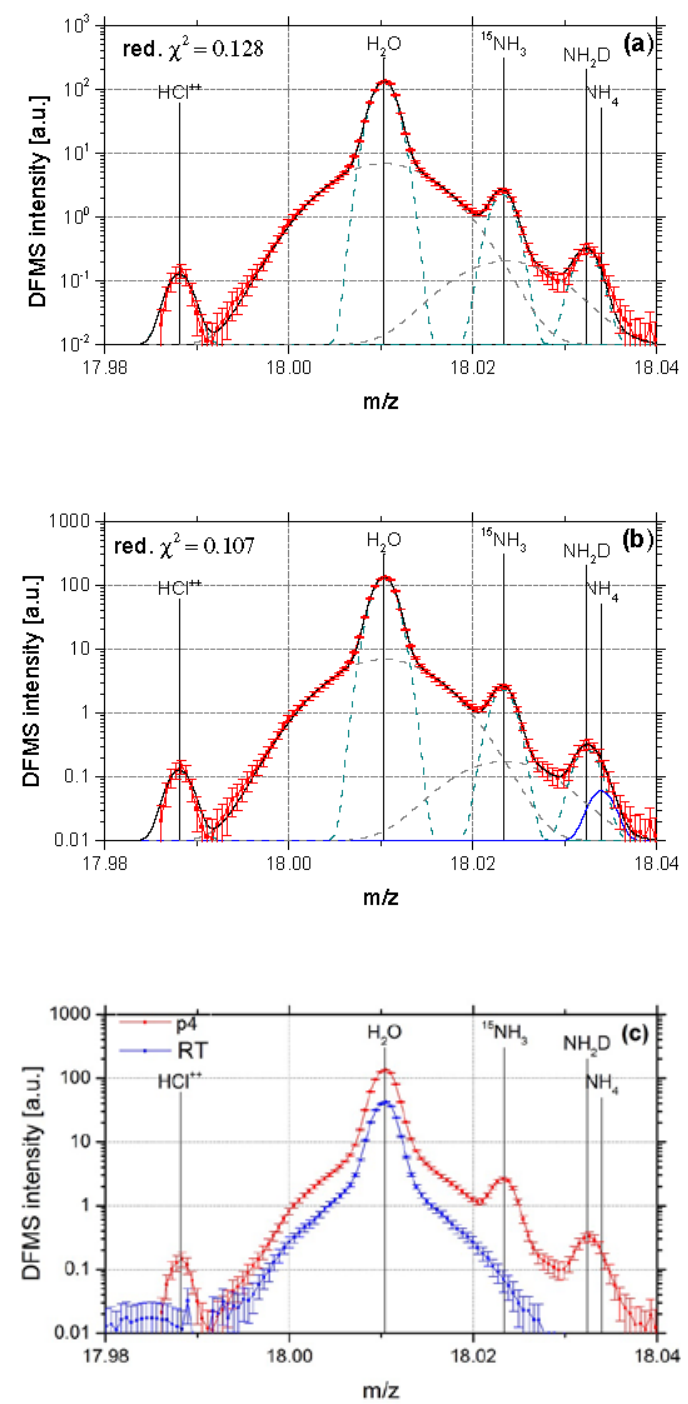

Figure S3. A comparison of the $\mathrm{p} 4$ mass spectrum at $\mathrm{m} / \mathrm{z}=18$ (red) fitted (a) without and (b) with $\mathrm{NH}_{4}$. Small and overlapping peaks are fitted with a single Gaussian. The reduced $\chi^{2}$ value of the fit decreases when a Gaussian at the position of $\mathrm{NH}_{4}$ is introduced. (c) The p4 data, collected at sample temperatures of about $90^{\circ} \mathrm{C}$, is compared to RT data only showing the central water peak as the salt sublimation rate is low. 
Table S2. Species observed in the $\mathrm{NH}_{4} \mathrm{Cl}$ experiments and their relative abundances calculated from fitting the p4 data set. Corrected peak areas (area corr.) are listed relative to $\mathrm{H}^{35} \mathrm{Cl}$ and in units of ions per $1.98 \mathrm{~s}$. Details on the error estimation are given in the main text.

\begin{tabular}{|c|c|c|c|c|c|}
\hline species & exact mass & sensitivity & area corr. & estimated error & area corr. rel. to $\mathrm{H}^{35} \mathrm{Cl}$ \\
\hline $\mathrm{N}$ & 14.0025 & 2.08 & $(\mathrm{~nm})$ & & \\
\hline $\mathrm{NH}$ & 15.0104 & 1.97 & $(\mathrm{~nm})$ & & \\
\hline $\mathrm{NH}_{2}$ & 16.0182 & 1.87 & $(\mathrm{~nm})$ & & \\
\hline $\mathrm{NH}_{3}$ & 17.0260 & 1.78 & 218028 & 0.36 & 1.475 \\
\hline${ }^{15} \mathrm{NH}_{3}$ & 18.0230 & 1.70 & 784 & 0.36 & $5.30 \mathrm{E}-03$ \\
\hline $\mathrm{NH}_{2} \mathrm{D}$ & 18.0323 & 1.70 & 85.2 & 0.58 & $5.77 \mathrm{E}-04$ \\
\hline $\mathrm{NH}_{4}$ & 18.0338 & 1.70 & 9.58 & 0.58 & $6.48 \mathrm{E}-05$ \\
\hline $\mathrm{N}_{2}$ & 28.0056 & 1.20 & $(\mathrm{~nm})$ & & \\
\hline${ }^{35} \mathrm{Cl}$ & 34.9683 & 1.00 & 41752 & 0.36 & 0.282 \\
\hline $\mathrm{H}^{35} \mathrm{Cl}$ & 35.9761 & 0.98 & 147861 & 0.36 & 1 \\
\hline${ }^{37} \mathrm{Cl}$ & 36.9654 & 0.96 & 13949 & 0.36 & 0.094 \\
\hline $\mathrm{H}^{37} \mathrm{Cl}$ & 37.9732 & 0.94 & 51236 & 0.36 & 0.347 \\
\hline $\mathrm{N}^{35} \mathrm{Cl}$ & 48.9714 & 0.73 & $(\mathrm{~nm})$ & & \\
\hline $\mathrm{NH}^{35} \mathrm{Cl}$ & 49.9792 & 0.75 & 1.15 & 0.58 & 7.77E-06 \\
\hline $\mathrm{N}^{37} \mathrm{Cl}$ & 50.9684 & 0.74 & 0.69 & 0.58 & 4.69E-06 \\
\hline $\mathrm{NH}_{2}{ }^{35} \mathrm{Cl}$ & 50.9871 & 0.74 & 43.9 & 0.36 & 2.97E-04 \\
\hline $\mathrm{NH}^{37} \mathrm{Cl}$ & 51.9763 & 0.73 & 0.22 & 0.58 & $1.49 \mathrm{E}-06$ \\
\hline $\mathrm{NH}_{3}{ }^{35} \mathrm{Cl}$ & 51.9949 & 0.73 & $(X)$ & & \\
\hline $\mathrm{NH}_{2}{ }^{37} \mathrm{Cl}$ & 52.9841 & 0.72 & 11.4 & 0.36 & $7.72 \mathrm{E}-05$ \\
\hline
\end{tabular}




$\begin{array}{llll}\mathrm{NH}_{4}{ }^{35} \mathrm{Cl} & 53.0027 & 0.72 & (\mathrm{X}) \\ \mathrm{NH}_{3}{ }^{37} \mathrm{Cl} & 53.9919 & 0.71 & (\mathrm{X}) \\ \mathrm{NH}_{4}{ }^{37} \mathrm{Cl} & 54.9997 & 0.70 & (\mathrm{X})\end{array}$

$(\mathrm{nm})$ not measured in the p1-p5 high statistics experiments.

(X) no signal within the error of the fit.

Table S3. Species observed in the ${ }^{15} \mathrm{NH}_{4} \mathrm{OO}{ }^{13} \mathrm{CH}$ experiment and their abundances relative to ${ }^{15} \mathrm{NH}_{3}$. Corrected peak areas (area corr.) are listed relative to ${ }^{15} \mathrm{NH}_{3}$ and in units of ions per 20 s. Only data between 13 and $49 \mathrm{~m} / \mathrm{z}$ is considered. Details on the error estimation are given in the main text.

\begin{tabular}{|c|c|c|c|c|c|}
\hline species & exact mass & sensitivity & area corr. & estimated error & area corr. rel. to ${ }^{15} \mathrm{NH}_{3}$ \\
\hline${ }^{13} \mathrm{C}$ & 13.0028 & 1.30 & 33924 & 0.36 & 0.00796 \\
\hline${ }^{13} \mathrm{CH}$ & 14.0106 & 1.22 & 27129 & 0.36 & 0.00636 \\
\hline${ }^{15} \mathrm{~N}$ & 14.9996 & 1.16 & 42472 & 0.36 & 0.00996 \\
\hline${ }^{13} \mathrm{CH}_{2}$ & 15.0185 & 1.16 & 2748 & 0.58 & 0.000645 \\
\hline $\mathrm{O}$ & 15.9944 & 1.10 & 119272 & 0.36 & 0.0280 \\
\hline${ }^{15} \mathrm{NH}$ & 16.0074 & 1.10 & 143165 & 0.36 & 0.0336 \\
\hline${ }^{13} \mathrm{CH}_{3}$ & 16.0263 & 1.10 & 203 & 0.58 & $4.76 \mathrm{E}-05$ \\
\hline${ }^{17} \mathrm{O}$ & 16.9986 & 1.05 & (sh) & & \\
\hline $\mathrm{OH}$ & 17.0022 & 1.05 & 2232557 & 0.36 & 0.524 \\
\hline${ }^{15} \mathrm{NH}_{2}$ & 17.0152 & 1.05 & 4981028 & 0.36 & 1.17 \\
\hline${ }^{13} \mathrm{CH}_{4}$ & 17.0341 & 1.05 & 711 & 0.58 & 0.000167 \\
\hline${ }^{18} \mathrm{OH}$ & 17.9986 & 1.00 & (sh) & & \\
\hline
\end{tabular}




\begin{tabular}{|c|c|c|c|c|c|}
\hline $\mathrm{H}_{2} \mathrm{O}$ & 18.0100 & 1.00 & 3673347 & 0.36 & 0.862 \\
\hline${ }^{15} \mathrm{NH}_{3}$ & 18.0230 & 1.00 & 4263125 & 0.36 & 1 \\
\hline${ }^{15} \mathrm{NH}_{4}$ & 19.0309 & 0.96 & 14136 & 0.36 & 0.00332 \\
\hline${ }^{13} \mathrm{C}^{15} \mathrm{~N}$ & 28.0029 & 0.70 & 1642 & 0.58 & 0.000385 \\
\hline${ }^{13} \mathrm{CO}$ & 28.9977 & 0.68 & 533726 & 0.36 & 0.125 \\
\hline $\mathrm{H}^{13} \mathrm{C}^{15} \mathrm{~N}$ & 29.0108 & 0.68 & 11654 & 0.58 & 0.00273 \\
\hline $\mathrm{NO} / \mathrm{C}^{18} \mathrm{O} /{ }^{15} \mathrm{~N}_{2}$ & 29.9986 & 0.66 & $(X)$ & & \\
\hline${ }^{13} \mathrm{CHO}$ & 30.0055 & 0.66 & 3623156 & 0.36 & 0.850 \\
\hline${ }^{13} \mathrm{CH}_{2}{ }^{15} \mathrm{~N}$ & 30.0186 & 0.66 & 8676 & 0.58 & 0.00204 \\
\hline${ }^{15} \mathrm{NO}$ & 30.9945 & 0.65 & 25900 & 0.36 & 0.00608 \\
\hline${ }^{13} \mathrm{C}^{18} \mathrm{O}$ & 31.0020 & 0.65 & 1066 & 0.58 & 0.000250 \\
\hline${ }^{13} \mathrm{CH}_{2} \mathrm{O}$ & 31.0134 & 0.65 & 9517 & 0.36 & 0.00223 \\
\hline${ }^{13} \mathrm{CH}_{3}{ }^{15} \mathrm{~N}$ & 31.0264 & 0.65 & 211 & 0.36 & 4.96E-05 \\
\hline${ }^{13} \mathrm{CH}^{18} \mathrm{O}$ & 32.0098 & 0.63 & 8178 & 0.36 & 0.00192 \\
\hline${ }^{13} \mathrm{CH}_{3} \mathrm{O}$ & 32.0212 & 0.63 & 42 & 0.58 & $9.92 \mathrm{E}-06$ \\
\hline${ }^{13} \mathrm{CH}_{4}{ }^{15} \mathrm{~N}$ & 32.0342 & 0.63 & 9.0 & 0.58 & $2.10 \mathrm{E}-06$ \\
\hline${ }^{13} \mathrm{CH}_{4} \mathrm{O}$ & 33.0290 & 0.62 & $(X)$ & & \\
\hline${ }^{13} \mathrm{CH}_{5}{ }^{15} \mathrm{~N}$ & 33.0421 & 0.62 & $(X)$ & & \\
\hline${ }^{13} \mathrm{C}^{15} \mathrm{NO}$ & 43.9979 & 0.49 & 7072 & 0.58 & 0.00166 \\
\hline${ }^{13} \mathrm{CO}_{2}$ & 44.9926 & 0.48 & 1428703 & 0.36 & 0.335 \\
\hline $\mathrm{H}^{13} \mathrm{C}^{15} \mathrm{NO}$ & 45.0057 & 0.48 & 48471 & 0.58 & 0.0114 \\
\hline${ }^{13} \mathrm{CHO}_{2}$ & 46.0005 & 0.47 & 4467632 & 0.36 & 1.05 \\
\hline${ }^{13} \mathrm{CH}_{2}{ }^{15} \mathrm{NO}$ & 46.0135 & 0.47 & 74780 & 0.58 & 0.0175 \\
\hline
\end{tabular}




$\begin{array}{llllll}{ }^{13} \mathrm{CO}^{18} \mathrm{O} & 46.9969 & 0.46 & 6942 & 0.58 & 0.00163 \\ { }^{13} \mathrm{CH}_{2} \mathrm{O}_{2} & 47.0083 & 0.46 & 4563166 & 0.36 & 1.07 \\ { }^{13} \mathrm{CH}_{3}{ }^{15} \mathrm{NO} & 47.0213 & 0.46 & 33924 & 0.36 & 0.0607 \\ { }^{13} \mathrm{CHO}^{18} \mathrm{O} & 48.0048 & 0.46 & 27129 & 0.36 & 0.00222 \\ { }^{13} \mathrm{CH}_{3} \mathrm{O}_{2} & 48.0161 & 0.46 & 258720 & 0.58 & 0.00280 \\ { }^{13} \mathrm{CH}_{4}{ }^{15} \mathrm{NO} & 48.0291 & 0.46 & 11943 & 0.58 & 0.000391 \\ { }^{13} \mathrm{CH}_{2} \mathrm{O}^{18} \mathrm{O} & 49.0126 & 0.45 & 1668 & 0.58 & 0.00550 \\ { }^{13} \mathrm{CH}_{5}{ }^{15} \mathrm{NO} & 49.0370 & 0.45 & (\mathrm{X}) & & \end{array}$

(sh) signal hidden under a large peak.

(X) no signal within the error of the fit. 